\title{
Occupant Well-Being and House Values ${ }^{\dagger}$
}

\author{
Richard H. Rijnks ${ }^{\ddagger} \quad$ Stephen Sheppard $\$$
}

August 29, 2020

\begin{abstract}
Recent research indicates that subjective evaluation of well-being increases when conditions of housing are improved. This suggests that subjective well-being might serve as a useful proxy for characteristics of a home or neighbourhood that are relevant to an occupant, but unobserved by the analyst. In this paper, we assess this idea through analysis of residential property valuation, using a sample of 95,413 respondents matched to house sales for 2000 to 2012 in the North of the Netherlands. Using a spatial econometric approach, we find a significant and positive association between individual and regional subjective well-being and house prices. This suggests that house buyers are willing to pay more for, or that house sellers require greater compensation to sell and move from, properties and areas in which the resident experiences greater happiness. Our study provides the first estimates of the importance of these effects.
\end{abstract}

Keywords: Subjective well-being, house price, hedonic model

JEL Classification: D91, R2, R3

Author(s) Conflict-of-interest: None

\footnotetext{
†We would like to thank Erik Johnson for helpful comments, and to acknowledge funding support from the University of Groningen, Campus Fryslân, and the Waddenacademie

${ }^{\ddagger}$ Department of Economic Geography, University of Groningen, Groningen, Netherlands

${ }^{\S}$ Department of Economics, Williams College, Williamstown, Massachusetts
} 


\section{Introduction}

Hedonic models popularised by Rosen (1974) and others are fundamental to analysis of prices in markets for differentiated commodities. In his paper, Rosen states that if "goods can be treated as tied packages of characteristics, observed market prices are also comparable on those terms." In hedonic models of house prices, these characteristics generally deal with characteristics of the property, and characteristics of the local environment. Treating houses as differentiated products, the transaction price paid for the house is a function of observed and unobserved characteristics of the house.

Unobserved characteristics pose difficulties in the estimation of the parameters of hedonic models, which requires data on all relevant characteristics of the product as noted in Bajari and Benkard (2005). Obtaining accurate estimates of the contribution to value of individual characteristics of properties relies on the assumption that the model is estimated using data on all characteristics, or at least that the unobserved characteristics are orthogonal to the characteristics used in the model. So long as these assumptions hold, the estimates obtained through a hedonic price model remain unbiased. However, if the unobserved characteristics are correlated with the observed characteristics, then the estimates of the contribution to value of the observed characteristics might be biased. Moreover, if these unobserved characteristics contain regional attributes, the model's residuals will be spatially correlated, violating the model's assumed independence of observations.

Recent progress in the field of happiness studies suggests an approach that might address some of these problems. Happiness as a measure of utility has been used in the field of economics since the seminal paper of Easterlin (1974), although until very recently the validity of measuring happiness was a hotly debated topic. Contributions by Diener and Suh (1997) and Veenhoven (2012) show that measures of self-reported happiness on the whole "measure what they set out to measure". This means that, following Frey and Stutzer (2002), rather than limiting studies to the observable choices made by individuals (e.g. moving house, purchasing decisions), incorporating measures of happiness allows for the study of utility in situ. We argue that the interpretation of happiness as a measure of utility means it can be used to estimate the value of unobservable structure or neighbourhood attributes. Interpreting happiness as a measure of well-being, a higher level of happiness implies that (ceteris paribus) a person is deriving greater benefit from their life-situation, including living in a certain house or neighbourhood. Including subjective well-being (SWB) in the hedonic price function as a measure of unobserved attributes will then improve the estimation of the hedonic price function.

This paper is not the first to use SWB as a measure of unobserved utility. Previously, Goetzke and Islam (2017) used measures of SWB to identify deviations from a spatial equilibrium of utility. The basis of their analysis is that in equilibrium SWB would be equal across space. They show, controlling for individual level variables, that there is evidence of a spatial disequilibrium with marginal rates of substitution of around $\$ 16,000$ to move from regions with the lowest values to the mean. In addition, Goetzke and Islam (2017) find that positive deviations from spatial equilibrium in SWB are associated with higher subsequent in-migration.

The link between neighbourhood location or housing characteristics and SWB has motivated several applications of SWB in the analysis of residential location or housing markets. For example, Stutzer and Frey (2008) examine the association between SWB and time spent commuting, and find a consistently negative relationship. Standard urban economic theory would suggest that increased commuting time is the implicit price paid for access to better labor markets or housing, and 
that in equilibrium the utility (and possibly the SWB) would be equal at all locations. They label the negative association as the "paradox of commuting" and offer some possible explanations including intra-household bargaining and frictions that keep households from reaching equilibrium. Dickerson et al. (2014) tackle this paradox econometrically, suggesting that while the association is negative and precisely estimated in pooled ordered logit models of SWB, the situation is less clear using fixed-effects or more exotic estimation techniques. Using these alternative estimation methods does not reverse the sign of the estimated relationship, but the magnitude is reduced and the variance of the estimator increased sufficiently so that we cannot say that the association is not zero, as theory might predict.

Other studies examine a more direct association between SWB and housing or neighbourhood characteristics. Foye (2017) is concerned with the impact of the living space provided by a house on the SWB of the occupants. He finds that increased living space is associated with increased SWB, and intriguingly that this relationship is gender-dependent. Cattaneo et al. (2009) evaluate the power of a project to improve the quality of slum housing in Mexico. Again focusing on SWB as the outcome measure, they apply a careful experimental design and discover that the improvements in house quality increase maternal life satisfaction and decrease stress. Ferreira and Moro (2010) also consider measured SWB as the outcome, in this case of environmental attributes, while they control for house prices.

The approach we take is different, focusing on the ability of measures of SWB and emotional affect to provide information about the unobserved or idiosyncratically-valued structure and neighbourhood attributes. Our analysis contributes to the literature on hedonic price estimation in two ways. First, we aim to show that including a direct measure of happiness on the right hand side of the hedonic price function helps control for unobserved variables at the individual household level. A positive and significant coefficient for happiness, with transaction price as the dependent variable, shows that a higher expressed level of SWB corresponds to higher transaction price paid by the owner. These deviations could correlate with things such as curb appeal, odours, and proximity to friends and family.

In addition to the individual unobserved attributes of the dwelling, the second contribution of this paper is to estimate the impact of unobserved neighbourhood effects, such as proximity of friends or quality of local public facilities. Using a spatial lag specification of the happiness variable, a positive and significant coefficient for lagged happiness would mean that higher utility in the neighbourhood, controlling for higher individual utility, corresponds to a higher transaction price. Together, these two specifications separate the effects on the transaction price of individual and local neighbourhood attributes that are approximately measured by expressed SWB. The outcomes provide a first estimate of the ratio of the individual and neighbourhood unobserved effects.

To obtain our estimates, we employ the spatial model developed by Kelejian and Prucha (2010) which allows us to incorporate a spatial econometric specification, as well as to explicitly control for possible endogeneity between the measure of occupant SWB and the transaction price. We adjust for the endogeneity of happiness and the (log of the) transaction price using an instrumental variables approach. We use the package 'sphet' in R to estimate the spatial models, discussed in Piras (2010).

The data we use in this study consists of a large scale $(95,413$ individuals) multi-generation biobank survey called Lifelines, the data-collection run used in this study was collected between 2006 and 2012 and focuses on the North of the 
Netherlands. The survey contains individuals' place of residence (addresses) and a large number of individual variables, including health, well-being, socio-economic status, and various psychometrics. From this study we obtain the residential locations of individuals and individual responses to questions relating to subjective well-being and positive and negative affect. These are then combined with data from the Dutch realtor association (NVM) which contains information on around $70 \%$ of real-estate transactions as described in Brounen and Kok (2011). The NVM dataset provides real-estate characteristics, such as transaction price and date, numbers of rooms, bathrooms, and size of property and lot. Finally, we add neighbourhood data from Statistics Netherlands (CBS) and neighbourhood crime data from the National Police.

\section{Hedonic analysis with unmeasured attributes}

Housing is a heterogeneous good consisting of varying quantities of attributes, which makes measurement of value and analysis of demand more difficult, as discussed in Sheppard (1999). Hedonic models allow the estimation of prices at the level of the relatively homogeneous component attributes (the implicit markets), facilitating valuation and analysis of the heterogeneous individual properties. The hedonic prices of these characteristics depend upon the household's willingness-topay (determined by the household's preferences and income) and the costs of bringing to market structures for sale, whether through new production or resale of existing structures.

There are two problems that arise from unobserved factors when estimating a hedonic price function. First, not all attributes related to the house or immediate neighbourhood are directly measurable, as discussed in Folmer et al. (2014). Second, as discussed in Niedomysl (2011), individual household preferences are difficult to measure or control for, which may be required if we are using data arising from diverse households in many communities.

The nature of these markets, as discussed by Bockstael and McConnell (2007), with properties that are structurally different and in different locations results in (at least) two sources of omitted variable bias: omitted variables related to the property or the buyers alone, and omitted variables related to the neighbourhood or environment. The first category of omitted variables contains those housing characteristics that are not usually measured but that do influence the price of the house. Data on some attributes such as noise and smell, might be available (perhaps through proxies) for larger sources of nuisance, e.g. airports or recycling stations as discussed in van Praag and Baarsma (2005) and Anselin and Lozano-Gracia (2008). For more modest sources, data are rarely available, or are time (and occupant) dependent, and very local in the extent of impact.

Beyond these localised external effects, structure design and layout may enhance the well-being of occupants but be difficult to measure or quantify even though they are readily observed by a prospective buyer. For such subjective considerations it might be expected that different combinations of attributes lead to different outcomes as discussed in Helbich et al. (2013). These property-level unobserved characteristics could significantly influence price, and, more importantly, they could be related to other measured attributes: the popularity of certain features (e.g. a kitchen island, double garage) are not time-invariant, implying a correlation with building period, property age, and other features such as insulation or maintenance status. In short, these specific and frequently unrecorded property features are unlikely to be orthogonal to the 
other factors included in the model.

A second category of unobserved attributes relates to the situation of the property within a wider region. Similar to the unobservable structural characteristics of the house, the location of each house is an important determinant of the price of the property. While the location of the house with respect to labor market opportunities is the central determinant of property values as noted by Tomkins et al. (1998), disamenities such as pollution and crime can result in lower transaction prices as found by van Praag and Baarsma (2005) and Anselin and Lozano-Gracia (2008). Analogous to the unrecorded characteristics of properties mentioned above, unrecorded or difficult-to-observe features of the residential neighbourhood can alter household well-being within that neighbourhood. Indeed Tivadar and Jayet (2019) argue that differentiation in willingness to pay for (local) amenities between more and less affluent buyers affects property values at the neighbourhood level. In their model of urban house price patterns, local amenities have a long term effect on house prices which in turn contributes to the generation of new amenities valued more specifically by wealthier individuals.

Even when local neighbourhood attributes are relatively well known, data availability can be poor, as noted by Jim and Chen (2009). Cheshire and Sheppard (2004) and Panduro et al. (2018) found that local amenities such as parks and the quality of schools affect observed transaction prices. Not all parks and open spaces are equivalent, nor is it easy to discern ex ante which specific amenities will affect transaction prices. For example, the report presented in Lloyds Bank (2016) introduced the "Waitrose effect" and found that proximity to supermarket chains could lead to price premia ranging from about one to nearly 39 thousand pounds, depending on which supermarket chain was located nearest a property. Price premia also varied from one region to the next. Grislain-Lerémy and Katossky (2014) find a similar variation regarding proximity to hazardous industrial facilities between three French cities, concluding that it is likely that dissimilarities in neighbourhoods and perceived risk likely explain the variation.

The heterogeneity of these impacts suggests that the value of some amenities will be highly location-specific, while others may affect much larger regions. At the very local scale, Fleming et al. (2018) show that reducing daily sunlight hours as a result of neighbourhood development in Wellington, New Zealand, is associated with a non-trivial decline in property values. Taking a more regional focus, regional image or regional branding can influence how attractive a region is as a destination for a household as noted by Rijnks and Strijker (2013) and Haartsen et al. (2013). These perceptions of an area interact with a variety of factors varying from individual residential history, to life course stages, and sense of place as discussed in Thissen et al. (2010).

Recent developments in research on spatial heterogeneity suggest that both the correlation between local amenities and desirability of the location (noted in Rijnks et al., 2018) and the correlation between property characteristics and desirability of the property (discussed in Helbich et al., 2013) might be spatially non-stationary. This spatial non-stationarity of the coefficients most likely results from an omitted spatial variable interacting with the variables of interest, as discussed in Billé et al. (2017).

For cross-sectional studies, the most common approach is the use of regional proxies (e.g. presence of forests and lakes) and regional dummies. Abbott and Klaiber (2011) are critical of the use of regional indicators at relatively small levels of spatial disaggregation for two reasons. First, they inhibit the ability to find spatial effects at scales smaller than those of 
the variables and, second, they capture some of the spatial effects of amenities at larger spatial scales meaning that the measured capitalisation is lower than the real capitalisation of these amenities.

A second method used to control for unobserved spatially autocorrelated effects is the use of spatial econometric models. Spatial Error models introduce a spatial component in the error term of a general linear model, and estimate the coefficients through maximum likelihood as discussed in Vega and Elhorst (2015). The spatial component in the error term represents a spatial process that is otherwise unaccounted for in the model. Although OLS estimates remain unbiased even when a spatial error model would be appropriate, the standard errors obtained are inefficient. This is corrected by using a spatial error model. The drawback of using this type of modelling is that the Spatial Error model provides no further information on the unaccounted for spatial process, other than its existence. In addition, because the Spatial Error model is estimated globally, it accounts for spatially autocorrelated individual variations in, for instance, preferences for amenities, through the model's error term.

\section{Subjective well-being and unobserved amenities}

One solution to the problem of unobserved or unmeasured amenities and spatial effects in cross-sectional studies is the inclusion of a proxy for these variables. Recent progress in research into happiness by inter alia Veenhoven (2012) and Diener and Suh (1997) suggests that SWB could be a reasonable proxy for the utility impacts of these unobserved factors.

The use of self-reported measures of happiness and SWB has been widespread in psychology has increased in the field of economics. Frey and Stutzer (2002) identify a number of benefits to using happiness as a complement to income in the economics literature, starting with Easterlin (1974) who examined the cross-sectional and longitudinal association between income and happiness. The analysis revealed that, although correlated cross-sectionally, income and happiness were not closely related in longitudinal studies. This "Easterlin paradox" suggested a conceptual separation between income and happiness, and required a nuanced use of SWB as a measure of utility. As suggested by Sen (1987) and Frey and Stutzer (2005), individual utility may be best thought of as being determined by consequential utility (resulting from conventional choice among alternatives) and procedural utility that is derived or emerges from a process, irrespective of the choice made. Some important attributes of housing consumption such as social capital and the external amenity derived from friendships and familiarity with the neighbourhood may emerge from such processes.

As noted above, while studies have examined the relationship between happiness and housing consumption, researchers do not agree about the positions of happiness and home-ownership relative to each other. Ferreira and Moro (2010) estimate the impacts of environmental factors on well-being, while controlling for municipal real-estate valuation on the right hand side. This interpretation of housing prices implies that the environmental factors which contribute to the utility derived by the residents is not fully reflected in the hedonic valuation of the property. The authors argue that market imperfections and imperfect information explain this discrepancy. In their analysis, they find no effect of housing prices on well-being (it is only included as a control and not as the main variable of interest). However, there are a number of limitations that could contribute to difficulties in estimating the relationship between house prices and subjective well-being, varying from the use 
of average house prices for the region (as opposed to individual structure price) and collinearity arising from inclusion of both income and house price on the right hand side.

The implied assumption that higher average neighbourhood house prices will, ceteris paribus, increase happiness seems questionable as suggested in Luttmer (2005). Reversing this problem, Cattaneo et al. (2009) show that government schemes to improve the quality of the dwelling have a positive effect on life-satisfaction in Mexico. This is in line with the theoretical expectations outlined in this paper where an improvement in the dwelling increases the overall utility derived from housing characteristics by that individual, and as the transaction incurs no financial costs on the home owner, the overall result is to improve SWB.

Interesting recent papers by Stotz (2019) and Clark and Díaz Serrano (2020) use German panel data providing measures of SWB derived from housing to examine how home ownership and moving to a new residence affects overall SWB and SWB derived from housing. The panel structure of their data permits examination of how the changes in SWB attenuate (or not) over time, although the lack of exact location data prevents analysis of the extent to which these effects are localised. Both of these papers show that the SWB derived from housing increases with home ownership. The analysis of Clark and Díaz Serrano (2020) shows that, restricting attention to households who purchase a house and move to a new location, the SWB derived from housing is positive, significant and does not fade with time. The new residences are clearly having an impact on utility derived from housing, even when the increased price of housing generates offsetting effects so that overall SWB exhibits reduced levels of change.

In this paper we build upon this observation in order to include unobservable housing characteristics and unobserved neighbourhood characteristics in an analysis of house values. The results presented in Cattaneo et al. (2009), reflect a special case where the government intervened to improve the quality of the housing, but in theory, the same principle applies to all housing characteristics.

We expect that happiness accounts for the utility that individuals derive from living in a certain dwelling which is not otherwise accounted for in the explanatory variables; occupant SWB captures the beneficial impact of unobserved characteristics of the dwelling and is positively associated with transaction prices. However, the characteristics of the neighbourhood play an important role in the utility derived from living in a certain place. If certain neighbourhoods provide higher levels of utility (ceteris paribus) to their residents, this means that regional happiness would be positively associated with the transaction prices in certain areas. Using spatially lagged functions of happiness, this paper aims to disentangle individual unobservable characteristics, related to the dwelling itself, and regional unobservable characteristics.

There are three potential pathways that, in theory, provide a link between measured levels of subjective well-being and the market value of residential property. These are not necessarily mutually exclusive but do involve differences in interpretation of the responses to surveys of subjective well-being as well as understanding of the mechanisms through which the value of structure and neighbourhood attributes are capitalised into house prices.

The pathways are that first, measured levels of subjective well-being (SWB) may directly proxy for desirable amenities of a structure or neighbourhood. If these attributes are observable to potential buyers when directly viewing the property, then buyers can condition their willingness to pay on the levels of such attributes present. 
This is similar to the relationship identified in Oswald and Wu (2010). Working with health survey data from US states, they show that state-specific differentials in measured SWB correlate very well with quality-of-life rankings of US states presented in Gabriel et al. (2003). These rankings, in turn, are based on the identification of compensating variation in housing costs and incomes. The essential idea is that higher quality of life is associated with those states having high house prices relative to prevailing income levels. The higher quality of life attracts migration into the area resulting in higher house prices, and the differential in house prices is a compensating variation for the attractive features of life in that location. Oswald and Wu (2010) find that state-specific differences in subjective well being are significantly correlated with these objectively measured compensating variations, interpreted as the "non-income elements of human well-being". This relationship, applied to the level of the individual property, would allow for interpreting occupant subjective well-being as a proxy for important attributes available at that location.

One might object that the presence of desirable but unobserved attributes alone would be unlikely to increase final utility, and hence unlikely to increase SWB, if the price that must be paid for them is high. In this sense unobserved attributes may be no different to other structure or neighbourhood characteristics. Lot size, for example, is reasonably regarded as a desirable characteristic of residential property. Lot size also generally increases as we move from the urban centre towards the urban periphery. This is a feature of equilibrium where the household consumes more land in locations where land is relatively less expensive. It does not imply that the household has achieved a higher level of utility, and indeed in an urban model we would expect the level of utility achieved to be invariant across locations for a given income class as discussed in Ballas and Tranmer (2012) and Goetzke and Islam (2017). If we think of SWB as a measurement of the achieved utility level and if we did not have observations on lot size, it might be argued to be a mistake to take expressed SWB as a "proxy" for lot size.

A second pathway is that a household may purchase a property with an ex ante expectation about the level of some amenities that might be experienced upon occupation, and the price they pay reflects this expectation. When the ex post outcome is known, those households whose expectations are exceeded may experience an increase in SWB due to this fortunate outcome. As a result, the price required to induce them to sell the property would increase and the increased SWB would provide a proxy for this unexpectedly high level of amenity.

Finally, a third pathway is that there may be some levels of amenity that emerge during the course of living in the property. An example of such emergent attributes would be the social capital that a household accumulates while living in a community. They learn whom to trust, who can be relied upon for advice about activities in the community, and come to identify persons with whom they can enjoy these activities.

One of the first papers to illustrate the existence of this effect was the interesting paper of DiPasquale and Glaeser (1999). The focus of their analysis is to identify the extent to which owner-occupants of residential property tend to devote more resources towards investing in social capital than renters. Mindful of the fact that home ownership itself can increase moving costs and lead households to remain longer in the community, they analyse the separate contribution of duration of residence on social capital formation. They find that the effect of increased duration of residence, separate from owner-occupation itself, contributes as much as $60 \%$ to $90 \%$ of the increased social capital formation among owner-occupants. 
As noted by Glaeser et al. (2002), this social capital is valuable and can be expected to rise and fall over the course of the life cycle. In the specific context of housing markets, Hilber (2010) finds that direct measures of social capital are greater in communities and neighbourhoods with an inelastic supply of housing, suggesting that stability of residence in the community encourages social capital accumulation. His analysis shows that increases in social capital are associated with increases in house prices and this, in turn, affects who will choose to live in the community. Fu (2005) also finds evidence that social and cultural capital is reflected in house prices, although the data used are less detailed and the analysis somewhat less robust.

Combined, these studies suggest that accumulation of social capital is an important contributor to household well-being and an ongoing component of life in communities. As this process proceeds, the aggregate level of social capital in the neighbourhood emerges and is capitalised into house prices. This increased availability of social capital may be measured indirectly by the increased subjective well-being of households in the area.

While the first pathway discussed above is more or less static, the other two pathways imply that SWB should be increasing over time as a household continues to reside in the community.

\section{A simple theory of hedonic estimation using SWB}

Before proceeding to outline the data we use and our empirical strategy, we first present a simple theoretical approach that provides a model of the first (and to some extent the second) of the pathways discussed in the preceding section. In this way we provide a more formal justification for the empirical analysis below.

We assume households have preferences that are additive-separable over three groups. A composite good $x$ measured as expenditure on goods other than structure and neighbourhood attributes; a group $y$ of attributes of structure and neighbourhoods for which we have observations, and a group $z$ of attributes of the structure or neighbourhood for which data are unobserved because the data are not observed or will only emerge over time. The utility function then takes the form:

$$
u(x, y, z)=\underbrace{u_{1}(x)}_{\text {utility from composite good }}+\underbrace{u_{2}(y)}_{\text {utility from observed attributes }}+\underbrace{u_{3}(z)}_{\text {utility from unobserved attributes }}
$$

Normalising the price of the composite good $x$ to be unity, we can derive compensated demands

$$
x_{c}\left(u, p_{y}, p_{z}\right), \quad y_{c}\left(u, p_{y}, p_{z}\right) \quad \text { and } \quad z_{c}\left(u, p_{y}, p_{z}\right)
$$

and the expenditure function

$$
E\left(u, p_{y}, p_{z}\right)=x_{c}\left(u, p_{y}, p_{z}\right)+p_{y} \cdot y_{c}\left(u, p_{y}, p_{z}\right)+p_{z} \cdot z_{c}\left(u, p_{y}, p_{z}\right)
$$

We assume that preferences are monotonic. We also assume that the unobserved attributes are desirable and we normalise utility representation so that when utility is 0 the compensated demand for the unobserved attribute is $z_{c}\left(0, p_{y}, p_{z}\right)=0$. 
Households have income $M$ so that $M=E\left(u, p_{y}, p_{z}\right)$. Then the willingness to pay for housing is given by

$$
H\left(u, p_{y}, p_{z}\right)=M-x_{c}\left(u, p_{y}, p_{z}\right)=p_{y} \cdot y_{c}\left(u, p_{y}, p_{z}\right)+p_{z} \cdot z_{c}\left(u, p_{y}, p_{z}\right)
$$

In a market where all house transactions were of units already built with fixed attribute quantities, units would sell for values determined by equation 4 , so for such markets this is a template for the hedonic price function.

If we have observed sales values $V^{i}$ along with attribute measurements $y^{i}$ and $z^{i}$ we could proceed to estimate this hedonic function $H$ by estimating parameters $\rho_{0}, \rho_{y}$ and $\rho_{z}$ in

$$
V^{i}=\rho_{0}+\rho_{y} \cdot y^{i}+\rho_{z} \cdot z^{i}+\varepsilon
$$

where $\varepsilon$ is an unobserved error term. Unfortunately, as discussed in the preceding sections, we lack observations of $z^{i}$ so that if we proceed to estimate equation 5 without such data our estimates of $\rho_{0}$ and $\rho_{y}$ will be biased and inconsistent. In this simple two variable case, the magnitude of the bias in the estimate of $\rho_{y}$ is widely familiar:

$$
\operatorname{plim} \rho_{y}=\rho_{z} \frac{\operatorname{Cov}(y, z)}{\operatorname{Var}(\mathrm{y})}
$$

Thus if the covariance between the observed attribute $y$ and the desirable unobserved attribute $z$ is positive, the estimate of $\rho_{y}$ will be biased upwards. When there are multiple observed and unobserved variables, the magnitude and direction of the bias is more complex, but the basic intuition remains intact.

In this setting, how might we proceed? To see the intuition of the idea being explored here, suppose we have a single unmeasured or unobserved attribute $z^{i}$. We expect that utility maximising households choose

$$
z^{i}=z_{c}\left(u, p_{y}, p_{z}\right)
$$

Taking a first-order Taylor series approximation, we have

$$
z^{i}=z_{c}\left(u^{i}, p_{y}, p_{z}\right) \approx z_{c}\left(0, p_{y}, p_{z}\right)+\frac{\partial z_{c}}{\partial u} \cdot u^{i}=\frac{\partial z_{c}}{\partial u} \cdot u^{i}
$$

Thus the unobserved attribute level $z^{i}$ could be approximated by, and is proportional to, the utility level of the household that successfully purchases the property. If we have a measure of the utility of the purchasing household, we could use that measure as a proxy for the unobserved attribute and estimate

$$
V^{i}=\rho_{0}+\rho_{y} \cdot y^{i}+\tilde{\rho_{u}} \cdot u^{i}+\varepsilon
$$

The estimated parameter $\tilde{\rho_{u}}$ will include both the 'pure' attribute price $\rho_{z}$ and the scaling factor $\frac{\partial z_{c}}{\partial u}$ (as well as some impact of the error of the Taylor approximation). Given that the unmeasured attributes are often characteristics or features 
that lack widely agreed units of measurement, this seems a small price to pay if it helps to reduce the bias in estimation of the hedonic relationship.

A reasonable measure to use for $u^{i}$ in equation 9 would be one of the indicators of subjective well-being that, while not universally available, are becoming more widely used and studied. In many circumstances it may be easier to collect these measures of SWB than to devise approaches to measure scenic view, social capital, quality of local schools, or other important but frequently unmeasured attributes.

The structure of the approximation and the role of utility level (as approximated by SWB) in providing a proxy for unmeasured attributes is made even more apparent when we consider specific utility functions. Consider, for example, the case where preferences can be represented by a Cobb-Douglas utility function. Then

$$
u(x, y, z)=(1-\alpha-\beta) \ln x+\alpha \ln y+\beta \ln z
$$

The compensated demand for and $z$ is then given by

$$
z_{c}=\frac{u}{(1-\alpha-\beta)^{1-\alpha-\beta}}\left(\frac{p_{y}}{\alpha}\right)^{\alpha} \cdot\left(\frac{\beta}{p_{z}}\right)^{1-\beta}
$$

In this case, the compensated demand is linear in the utility level so the Taylor approximation used above is exact. The estimated parameter $\tilde{\rho_{u}}$ in equation 9 is then

$$
\tilde{\rho_{u}}=\frac{\rho_{z}^{\beta} \cdot \beta^{1-\beta}}{(1-\alpha-\beta)^{1-\alpha-\beta}}\left(\frac{\rho_{y}}{\alpha}\right)^{\alpha}
$$

and we see that the utility of the buyer provides a good proxy for the relevant unobserved attributes. This case is easily generalised to more than one unobserved attribute, although the algebraic expression linking the estimated 'price' of SWB to the prices of unobserved attributes becomes necessarily more complex.

\section{Data and empirical strategy}

\section{Data}

The two main datasets used in this study are from the Lifelines Biobank study and the Dutch Association of Realtors and Appraisers (NVM) data on real-estate transactions. The Lifelines Biobank is a multi-generational cohort study used to assess multi-morbidity and multi-generational health in the North of the Netherlands (discussed in more detail in Scholtens et al., 2015)). Figure 1 illustrates the region from which the data were collected.

In addition to the Lifelines and NVM data, we make use of data from Dutch National Statistics to obtain population density and the share of population with a non-western heritage. Table 1 lists and describes the variables used in the analysis, along with the source of the data and the measurement level of the variables. 
Figure 1: The north of the Netherlands

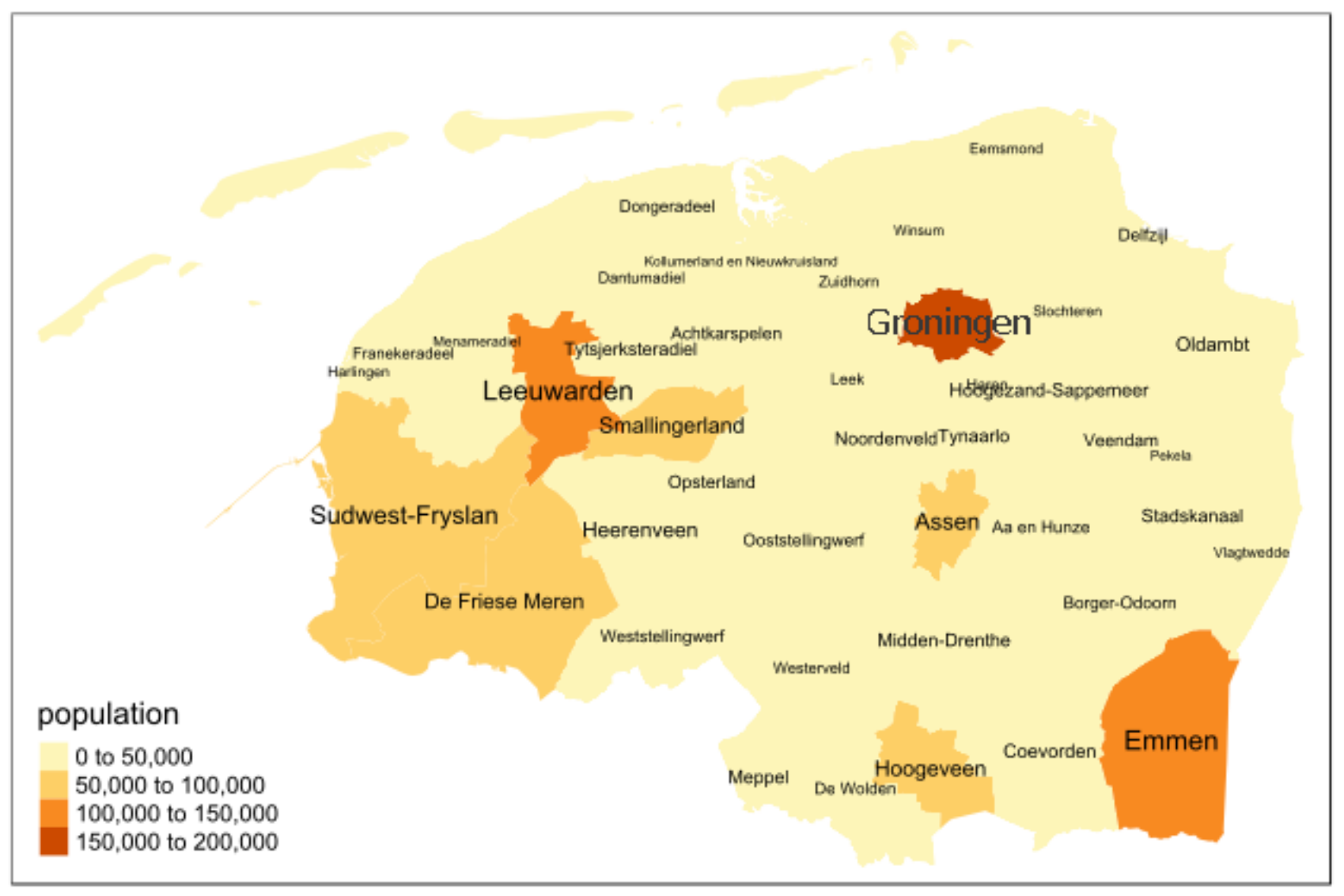


Table 1: Variables used in analysis

\begin{tabular}{|c|c|c|c|}
\hline Variable & Source & Measurement level & Description \\
\hline $\operatorname{Ln}($ floor area $)$ & NVM & Property & Natural log of floorspace in the house, natural numbers, missings deleted. \\
\hline Ln(lotsize) & NVM & Property & Natural log of one plus square meters lot size, natural numbers, missings deleted. \\
\hline $\operatorname{Ln}($ rooms $)$ & NVM & Property & Natural log of the number of rooms \\
\hline Ln(bathrooms) & NVM & Property & Natural log of the number of bathrooms \\
\hline Balcony & NVM & Property & Dummy indicating presence of one or more balconies \\
\hline Parking & NVM & Property & Dummy for private parking $1=$ yes \\
\hline Basement & NVM & Property & Dummy for basement $1=$ yes \\
\hline $\begin{array}{l}\text { Attic } \\
\text { Under roof }\end{array}$ & $\begin{array}{l}\text { NVM } \\
\text { NVM }\end{array}$ & $\begin{array}{l}\text { Property } \\
\text { Property }\end{array}$ & $\begin{array}{l}\text { Dummy for attic } 1=\text { yes (in other markets called a "Loft" space) } \\
\text { Dummy for under roof storage area } 1=y e s \text { (in other markets called an "Attic" space) }\end{array}$ \\
\hline Monument & NVM & Property & Dummy for listed building $1=$ yes \\
\hline Monumental & NVM & Property & Dummy for monumental appearance (assessed by realtor) $1=$ yes \\
\hline Maintin & NVM & Property & Quality of maintenance indoors (assessed by realtor) $1=$ poor through $9=$ excellent \\
\hline Maintout & NVM & Property & Quality of maintenance outdoors (assessed by realtor) $1=$ poor through $9=$ excellent \\
\hline Insulation & NVM & Property & $\begin{array}{l}\text { Measurement of level of insulation (assessed by realtor), } 0=\text { no insulation, } 1=\text { one type of } \\
\text { insulation, } 5=\text { fully insulated }\end{array}$ \\
\hline Ln(urban distance) & CBS & Property & Natural log of distance from property to centroid of nearest major municipal area. \\
\hline upto1905 & NVM & Property & Building period for the property (dummies), reference category is built between 2000 and 2012 . \\
\hline upto1930 & NVM & Property & \\
\hline upto1944 & NVM & Property & \\
\hline upto1959 & NVM & Property & \\
\hline upto1970 & NVM & Property & \\
\hline upto1980 & NVM & Property & \\
\hline upto1990 & NVM & Property & \\
\hline upto2000 & NVM & Property & \\
\hline Ln(density) & CBS & Municipality & Natural log of population per square kilometer, at the municipal level. \\
\hline $\operatorname{Ln}($ foreign $)$ & CBS & Municipality & Natural log of $1+$ percentage of population with a non-western background. \\
\hline Ln(burglary) & Politie & Municipality & $\begin{array}{l}\text { Natural log of } 1+\text { number of burglaries per } 10,000 \text { inhabitants in a municipality (2012), published } \\
\text { by Dutch Police. }\end{array}$ \\
\hline Ln(well-being) & Lifelines & Individual & Natural log of $1+$ RAND-36 survey tool, component: Emotional well-being. \\
\hline
\end{tabular}


... continued from previous page:

\begin{tabular}{llll} 
Variable & Source & Measurement level & Description \\
\hline & & & \\
Ln(positive affect) & Lifelines & Individual & Natural log of $1+$ PANAS Positive affect scale. \\
Lag Ln(well-being) & Lifelines & Individual & Spatial lagged value of natural log of $1+$ emotional well-being. \\
y2000 & NVM & Property & Transaction year indicators, reference category is 2012. \\
y2001 & NVM & Property & \\
y2002 & NVM & Property & \\
y2003 & NVM & Property & \\
y2004 & NVM & Property & \\
y2005 & NVM & Property & \\
y2006 & NVM & Property & \\
y2007 & NVM & Property & \\
y2008 & NVM & Property & \\
y2009 & NVM & Property & \\
y2010 & NVM & Property & \\
y2011 & NVM & Property & \\
\hline
\end{tabular}


Data collection of the initial survey started in 2006, with data included in this survey up to and including 2012. There were three ways individuals could join the study. First, individuals aged 25 to 50 were approached through their general practitioner, resulting in a 24.5 per cent response rate. Those who participated were then requested to list their immediate family, who were subsequently invited. This second set yielded a response rate of 70.2 per cent. Finally, individuals who were not personally approached could enlist through a general website.

The data we use in this study are from the initial data release of 2013 with data from the baseline questionnaire which was administered to all individuals when they joined the study, comprising a total of 95,413 individuals. Klijs et al. (2015) report that the study is broadly representative of the population in the North of the Netherlands, with minor differences in gender composition (slightly higher percentage of female participants) and middle-aged individuals (as per the original survey characteristics).

The data from the Lifelines questionnaire are matched with real-estate transaction data from the NVM. The NVM data provide information on the most recent transactions for 153,030 properties in the years 2000-2012 in the North of the Netherlands. As Brounen and Kok (2011) note, the NVM dataset covers about 70 per cent of the Dutch private real estate market with Debrezion et al. (2011) stating that the scope of the dataset provides enough randomness to alleviate concerns regarding selection bias. The datasets were cross-matched based on addresses leaving a total of 18,184 properties for which both real-estate transaction data and Lifelines questionnaire data were available. Selecting those properties for which occupant SWB data were available, leaves a total of 16,645 property-occupant matches in the dataset. The nature of the dataset means we obtain measures of occupants after the transaction of the property occurred.

Selection into either one of our two main datasets could pose problems. First, the NVM dataset contains around $70 \%$ of private property transactions. However, other than the statement by Debrezion et al. (2011) there is little empirical data available to assess the representativeness of the dataset. According to the Dutch National Statistics (CBS) (2018b) the total number of properties sold was 232,637 , which would have the NVM dataset at $65.8 \%$ for the north of the Netherlands, meaning this subset contains broadly the same level of representativeness as used by Brounen and Kok (2011) and Debrezion et al. (2011).

When we match the two main data sources, we exclude both those property transactions without a corresponding observation in the Lifelines dataset, and those Lifelines participants in a residence without a recorded sale in the NVM dataset. From the Lifelines survey design, we know that a relatively large proportion of respondents will be between 25 to 50 years old, which might have some bearing on the types of homes in the dataset. To check for undue influences, we compare average price, floor space, and lot size between the matched datasets and the NVM total dataset. We find few discrepancies between the matched dataset and the NVM dataset overall. Table 2 provides a schematic description of the number of observations from each source used, and indicates the number of observations remaining after each refinement of the data. 
Table 2: Data observations available and excluded

\begin{tabular}{lccc} 
& Lifelines & $\begin{array}{c}\text { Source } \\
\text { Merged }\end{array}$ & NVM \\
\hline Observations available & 95,413 & & 191,804 \\
With location information & 75,292 & & $\downarrow$ \\
In North of Netherlands & 74,074 & $\downarrow$ & 190,411 \\
With data on lotsize and parking & $\downarrow$ & & 153,030 \\
Keep only most recent sale & $\downarrow$ & & $\swarrow$ \\
& $\searrow$ & & \\
Observations successfully merged & & 18,184 & \\
With socio-economic data & & 18,010 & \\
With subjective well being and affect & & 17,439 & \\
Lotsize $<100,000$ m ${ }^{2}$ & & 17,428 & \\
Floor area $>0$ & & 17,231 & \\
With (bath-)room data & & 15,409 & \\
Price $<€ 100$ million & & 15,407 & \\
Price $\geq € 1000$ & & 15,397 & \\
With reliable geocode & & 15,171 & \\
With some obs in neighbor cells & & 14,857 & \\
\hline
\end{tabular}

Tables 3 and 4 provide descriptive statistics for variables used in the analysis.

The NVM are the source of most data on structure characteristics. NVM instructions for measuring floor area provide the net square meters within the house, excluding areas within a room that are less than 1.5 meters high, and excluding rooms which are less than 2 meters high, or otherwise suitable for storage only. Lofts, attics, and basements are included in this measurement provided they have more than 4 square meters floorspace with a standing height of over 2 meters, and a window.

Lot size is measured in square meters of land area taken from the national land registry, although apartments are recorded as having zero land area. Therefore 1 is added to all lot size measures to enable use of natural logs in measuring area.

Urban centres in the North of the Netherlands have been defined using a compound measure that combines population density and population size. Using only size would lead to some large but essentially rural municipalities being included as urban centers. Súdwest Fryslân is the largest municipality by land area and has a higher population than Drenthe's provincial capital Assen, although it is mostly a rural municipality.

Similarly, Harlingen is one of the most densely populated municipalities in the North of the Netherlands, but that is mainly the result of the municipal boundary following the urban boundary closely, and the total population of Harlingen is just over 15,000. The compound measure resulted in four urban centers: Groningen, Leeuwarden, Assen, and Zwolle. Zwolle is located just to the south of the study area, but given the size of the city it is appropriate to include the distance to this city. The distance used in the models is the (Euclidean) distance to the nearest major urban center for each observation.

\footnotetext{
${ }^{\dagger}$ Flats have no recorded lotsize so that $\operatorname{Ln}($ lotsize +1$)=0$. Other properties have minimum values for this variable greater than 0.
} 
Table 3: Descriptive statistics for model variables

\begin{tabular}{lrrrr} 
Variable name & Mean & Std Dev & Min & Max \\
\hline Property sales price & 200,311 & 96,523 & 18501 & 2450000 \\
Ln(sales price) & 12.118 & 0.412 & 9.826 & 14.712 \\
Ln(positive affect) & 1.511 & 0.095 & 0.693 & 1.792 \\
Ln(well-being+1) & 4.366 & 0.207 & 0 & 4.615 \\
Ln(lag well-being+1) & 4.381 & 0.057 & 3.219 & 4.615 \\
Ln(urban distance) & 2.443 & 1.154 & -4.216 & 3.862 \\
Ln(density) & 5.904 & 0.942 & 4.007 & 7.797 \\
Ln(foreign+1) & 1.633 & 0.469 & 0.693 & 2.485 \\
Ln(burglary+1) & 3.294 & 0.508 & 1.902 & 4.055 \\
Ln(floor area+1) & 4.813 & 0.290 & 3.555 & 6.223 \\
Ln(lotsize+1) & 5.399 & 1.742 & 0 & 11.195 \\
Ln(rooms) & 1.541 & 0.260 & 0 & 3.526 \\
& Dichotomous & Variables & & \\
Two Bathrooms & 0.056 & 0.0019 & 0 & 1 \\
Three Bathrooms & 0.001 & 0.0002 & 0 & 1 \\
Balcony & 0.126 & 0.332 & 0 & 1 \\
Parking & 0.605 & 0.489 & 0 & 1 \\
Basement & 0.936 & 0.245 & 0 & 1 \\
Attic & 0.344 & 0.475 & 0 & 1 \\
Under Roof Area & 0.143 & 0.350 & 0 & 1 \\
Listed & 0.004 & 0.065 & 0 & 1 \\
Monument & 0.007 & 0.082 & 0 & 1 \\
\hline
\end{tabular}

The population density of the municipality containing the house is included as an additional control for effects of smaller population centers (rural towns and large villages).

The official classification of "Non-western foreigners" in Dutch statistics is people who have a migration history (their own or at least one of their parents) from Africa, Latin-America, Asia, or Turkey, excluding Indonesia and Japan, as described in Dutch National Statistics (CBS) (2018a). We include 1 plus the percentage of population with a non-western background in the municipality containing the house as a proxy for ethnic diversity in the neighbourhood.

From Table 4 we see that just over 60\% of the properties in the sample were constructed in the 1970's or later. The median sales date of properties in the sample is mid-2006.

\section{Operationalisation of main variables}

The use of subjective measures of happiness has seen tremendous progress over recent decades, although the field has yet to reach consensus on which measures are preferable, as noted by Frey and Stutzer (2002). Generally, three distinct constructs of happiness are evaluated which capture separate but complementary information on overall subjective well-being. The first component of overall subjective well-being is the general happiness or general life satisfaction component. This is measured either through a single survey item (e.g. all things considered, how satisfied are you with your life these days?) or preferably 
Table 4: Descriptive statistics for indicator variables

\begin{tabular}{|c|c|c|c|}
\hline Variable & Mean & Variable & Mean \\
\hline \multicolumn{2}{|c|}{ Interior maintenance } & \multicolumn{2}{|c|}{ Exterior maintenance } \\
\hline Interior 1 (Poor) & 0.10 & Exterior 1 (Poor) & 0.11 \\
\hline Interior 2 & 0.07 & Exterior 2 & 0.02 \\
\hline Interior 3 & 0.66 & Exterior 3 & 0.48 \\
\hline Interior 4 & 0.24 & Exterior 4 & 0.26 \\
\hline Interior 5 & 5.18 & Exterior 5 & 4.84 \\
\hline Interior 6 & 2.79 & Exterior 6 & 3.06 \\
\hline Interior 7 & 77.24 & Exterior 7 & 78.33 \\
\hline Interior 8 & 1.47 & Exterior 8 & 1.41 \\
\hline Interior 9 (Excellent) & 12.25 & Exterior 9 (Excellent) & 11.50 \\
\hline \multicolumn{2}{|c|}{ Construction period } & \multicolumn{2}{|c|}{ Year property sold } \\
\hline Up to 1905 & 4.35 & $Y_{2000}$ & 5.47 \\
\hline $1906-1930$ & 9.65 & $Y_{2001}$ & 6.91 \\
\hline 1931-1944 & 7.39 & $Y_{2002}$ & 7.98 \\
\hline 1945-1959 & 5.18 & $Y_{2003}$ & 8.05 \\
\hline 1960-1970 & 12.98 & $Y_{2004}$ & 8.79 \\
\hline 1971-1980 & 22.51 & $Y_{2005}$ & 10.24 \\
\hline 1981-1990 & 13.81 & $Y_{2006}$ & 11.05 \\
\hline $1991-2000$ & 18.82 & $Y_{2007}$ & 9.51 \\
\hline \multirow[t]{2}{*}{2000 and later } & 5.31 & $Y_{2008}$ & 8.64 \\
\hline & & $Y_{2009}$ & 6.95 \\
\hline \multicolumn{2}{|l|}{ Insulation } & $Y_{2010}$ & 6.43 \\
\hline No insulation & 9.99 & $Y_{2011}$ & 5.53 \\
\hline 1 type of insulation & 32.52 & $Y_{2012}$ & 4.45 \\
\hline 2 types of insulation & 13.58 & & \\
\hline 3 types of insulation & 12.48 & & \\
\hline 4 types of insulation & 10.94 & & \\
\hline Fully insulated & 20.50 & & \\
\hline
\end{tabular}

a compound measure using a set of questions as suggested in Kahneman and Krueger (2006). The general happiness or general life satisfaction component is used to measure a cognitive evaluation of the quality of life by the respondent.

The measurement used for this study is drawn from the SF-36 item short form survey. The SF-36 survey is one of the most widely used approaches to measuring health related quality of life, and is surveyed in Hays and Morales (2001). The survey groups 36 items into eight separate constructs. Seven of these deal with a variety of issues relating to physical health, subjective health, social functioning, and experienced limitations and pain. The construct from SF-36 we use in this study is Emotional well-being. Emotional well-being is measured on a 0 to 100 scale by weighting and adding together the underlying items, which are the extent an individual felt happy, nervous, depressed, calm, and downhearted over the past four weeks. The responses then averaged for each individual. The measure is tested for internal reliability (Cronbach's Alpha $=0.83$ ), showing that the underlying items are reliably correlated. Spatial lags of this variable were considered at $1,2.5,5$ and 10 kilometers, using an inverse euclidean distance weighting. 
The general SWB scores could be confounded with short term mood and whether or not the participant had recently been subjected to positive or negative events. Several studies show significant deviations for life-satisfaction based on mood (for example, Yap et al. (2017)) although these results were less or not significant on replication. In our analysis, we control for these positive transitory events, or temporal mood, by including the positive affect score obtained through the PANAS measurement tool discussed more fully in Watson (1988).

Correlations between happiness and transaction price could be the function of buyer optimism: optimistic individuals, indicated by positive affect, may be more likely to overestimate the positive outcomes of their decision as suggested in Nygren et al. (1996), although Isen et al. (1988) and Nygren et al. (1996) also find that the same individuals are more loss-averse. The estimated consequential utility by optimistic individuals leads to higher transaction prices, as a function of the overestimation of positive outcomes. To avoid confounding optimism related to consequential utility with SWB as a measure of procedural utility, this optimism needs to be controlled through a measure of positive affect.

There are several important concerns relating to the measurement of positive affect in the Lifelines dataset. The PANAS scales have been extensively validated using relatively short time spans (see for example Crawford and Henry (2004)). Generally the questions pertain to the most recent week. In the Lifelines survey, the questions are framed for the past four weeks. The validation of such longer time frames is less frequently undertaken, but Watson (1988) finds that positive affect (and negative affect) reliability remain high, even with time frames of up to a year.

Based on the evaluation of correspondence between the population and samples mentioned above we find the Lifelines data are broadly representative for the home-owning population in the North of the Netherlands. In addition, for SWB we find there is very little difference between the Lifelines data as a whole and the matched data subset used on our estimation. From this, we conclude that our data are broadly representative for the North of the Netherlands.

\section{Econometric specification}

Our goal is to explore whether the inclusion of SWB improves the estimation of hedonic models. To this end, we estimate three ordinary least squares models identified in Table 5. Model [1] uses property characteristics only; model [2] uses property and neighbourhood characteristics, and model [3] uses property and neighbourhood characteristics and adds SWB and positive affect. These three models are then assessed using the Akaike Informetion Criterion (a Log-Likelihood, penalised for additional degrees of freedom), with lower AIC's reflecting a better fit.

Second, we suspect there are various ways in which unobserved variables associated with SWB might be associated with transaction price paid, e.g. a recent financial windfall may result in a higher than expected willingness to pay as well as a higher (short term) SWB. We address the suspected endogeneity between SWB and transaction price, using instrumental variable regression, with SWB as the endogenous variable, and instrumenting with self-reported health [4], and self-reported pain [5]. Diener et al. (1999) found that self-reported health is positively associated with SWB, which implies that the instrument is correlated with the endogenous variable. The second condition that needs to be satisfied is that there is no direct effect of health on transaction price, and as far as we can ascertain, there is no plausible evidence that health directly 
Table 5: Summary of models estimated

OLS Models: Baseline hedonic models

$\begin{array}{llll}1 & Y=\beta_{0}+X_{\text {prop }} \beta_{\text {prop }}+\epsilon & \beta_{\text {prop }} & \begin{array}{l}\text { Vector of parameter estimates for property } \\ \text { characteristics }\end{array} \\ 2 & Y=[1]+X_{\text {neigh }} \beta_{\text {neigh }}+\epsilon & \beta_{\text {neigh }} & \begin{array}{l}\text { Vector of parameter estimates for neighbourhood } \\ \text { characteristics }\end{array} \\ 3 & Y=[2]+X_{p a} \beta_{p a}+X_{s w b} \beta_{s w b}+\epsilon & \beta_{p a} & \begin{array}{l}\text { Parameter estimates for positive affect } \\ \beta_{s w b}\end{array} \\ & \text { Parameter estimates for individual well-being }\end{array}$

IV Models: Exogenous estimate of SWB (first stage)

4 [3] with $S \hat{W} B_{h}=\pi_{0}+\pi_{h}$ Inst $_{h}+v$

First stage estimation of SWB using health as instrument

5 [3] with $S \hat{W} B_{h p}=[4]+\pi_{p}$ Inst $_{p}$

First stage estimation of SWB using health and pain as instruments

Spatial models: GMM estimates of [3], with sîwb [5] adding neighbourhood effect and spatially correlated errors
$6 \quad Y=\ldots+\lambda W Y+u$
$\lambda W Y$
$u=\rho W u+\epsilon$
$\rho W u$
Spatial autocorrelation of property prices
$7 \quad Y=[6]+\theta W X_{s w b}$
$\theta W X_{s w b}$
Spatial correlation of the error term
Effect of neighbourhood SWB on property prices

affects house prices. Some recent research, such as Atalay et al. (2017) and Fichera and Gathergood (2016), suggests that changes in house prices correspond to health outcomes. The proposed causal mechanism links a post-transaction increase in median neighbourhood house price, taken as a proxy for wealth, to increases in health. Since the possible changes in median neighbourhood income and subsequent health would occur after this transaction price, they are temporally exogenous to the transaction price paid, satisfying this second condition. We assess the instrumental variables regression with the usual diagnostics, testing for endogeneity in the OLS (Durbin-Wu-Hausman), we test for weak instruments, and we add selfreported pain as a second instrument to test for the overidentifying-restrictions.

Having established the appropriate a-spatial model, we proceed with the estimation of the generalized methods of moments spatial models ${ }^{2}$. As Vega and Elhorst (2015) note, there are a number of ways in which spatial relationships can be modeled. A key principle of spatial econometric models is that there is a spatial component to the data generating process. There are three positions where spatial structures may enter into the data generation process, a spatially autocorrelated dependent term $(\lambda W Y)$, spatial autocorrelation in one or more of the independent terms $(W X \theta)$, and a spatial disturbance term $(\rho W u)$, and all combinations of these three spatial terms. The general nested spatial model (Vega and Elhorst, 2015) is:

$$
Y=\lambda W Y+\alpha i_{N}+X \beta+W X \theta+u, u=\rho W u+\epsilon
$$

The $\lambda W Y$ term is used when a higher value for the dependent term in one region directly influences the value for the

\footnotetext{
${ }^{2}$ The standard spatial econometric literature and the GMM estimates differ in the symbols used for the spatial terms. For consistency, we maintain the Piras (2010) notation throughout
} 
dependent term in the neighboring region. For example, when putting a property up for sale, previous transaction prices in the neighbourhood may be used as a guidance for the asking price, or an increase in rents in one region of a city might directly impact rents in neighboring areas as demand spills over administrative boundaries. The $W X \theta$ term is used to model the spatial effects of characteristics on neighboring property prices. Spatial externalities will likely extend over some distance. For instance, the rate of property crime in one neighbourhood might affect house prices in that neighbourhood, but this negative effect might also spill over into contiguous neighbourhoods as a larger area gains an unfavorable reputation. In our models, we operationalize regional unobservables by neighbourhood subjective well-being, which allows us to separate the neighbourhood effects from the individual effects. Finally, the $\rho W u$ accounts for spatial autocorrelation in the error term, meaning that spatial clustering in unobservable variables (orthogonal to the model determinants) is accounted for. We use robust Lagrange Multiplier tests for the Spatial Error specification, and the spatial autoregressive dependent variable specification (see Anselin and Lozano-Gracia (2008) for further discussion). The standard modelling approach using spatial econometrics does not allow for the estimation of the IV models. More recently, the package sphet (Piras, 2010) has been implemented in $\mathrm{R}$ which enables the estimation of explicit two stage least squares spatial model, using a generalized method of moments estimation procedure (Piras, 2010). The $W X \theta$ is not a part of the original model, but has been added by creating a lagged version of the well-being variable.

We expect this spatially lagged variable of SWB to act as a measure of neighbourhood unobservable variables. Following Anselin and Lozano-Gracia (2008), we assess the models' robust Lagrange Multiplier test scores, and add these spatial structures to the model specifications. We start from a GNS specification, restricting the lagged independent variables to SWB. The spatial lag was constructed using the 'spdep' package in R (see Bivand and Wong, 2018; Bivand et al., 2013, for details). Related observations were weighted inversely to the Euclidean distance between the properties $1 / d$, with a maximum distance of 1 kilometer emphasising neighbors in close proximity. We used a row-standardized spatial weights matrix to account for heterogeneity in the number of neighbors. As a robustness check results were run with a bandwidth of 2.5 kilometers, which returned similar results.

There are a number of potential estimation issues with the GNS specification (for a full discussion, see Elhorst, 2014). From a theoretical point of view, a formal proof of the identification of a GNS model is not yet available. From a practical point of view, numerical issues arise depending on the structure of the spatial weights matrix, and identification issues may occur if all RHS variables are lagged. Our neighbors matrix specification is permissible, as we use an inverse weighting scheme with a cut off boundary. Elhorst (2014) characterise it as a border case, so we estimate an SAC model as a complement: large differences or sign reversals between the estimates for the spatial components between the SAC and GNS model will indicate that there are estimation issues. The SAC model restricts the spatially lagged independent term for SWB to 0 , and does not suffer from the estimation issues associated with the GNS. In addition, the SAC model provides a baseline against which we can compare the impact of including the lagged SWB term. Finally, we test the robustness of the results using a series of spatial bandwidths, see Abbott and Klaiber (2011), who state that different amenities interact with capitalization on different scales. 


\section{Results}

\section{Subjective well-being and time in residence}

Since a focus of our analysis is to evaluate the use of SWB in the analysis of house prices, we first consider how measured SWB evolves over the course of residence. As shown in Figure 2, our data include households who have been in residence for as little as 100 days to as many as 4500 days. As we noted above for at least two of our three pathways that might link SWB to structure and neighbourhood attributes, we would expect SWB to rise over time.

Figure 2: Distribution of observations of time in residence (days)

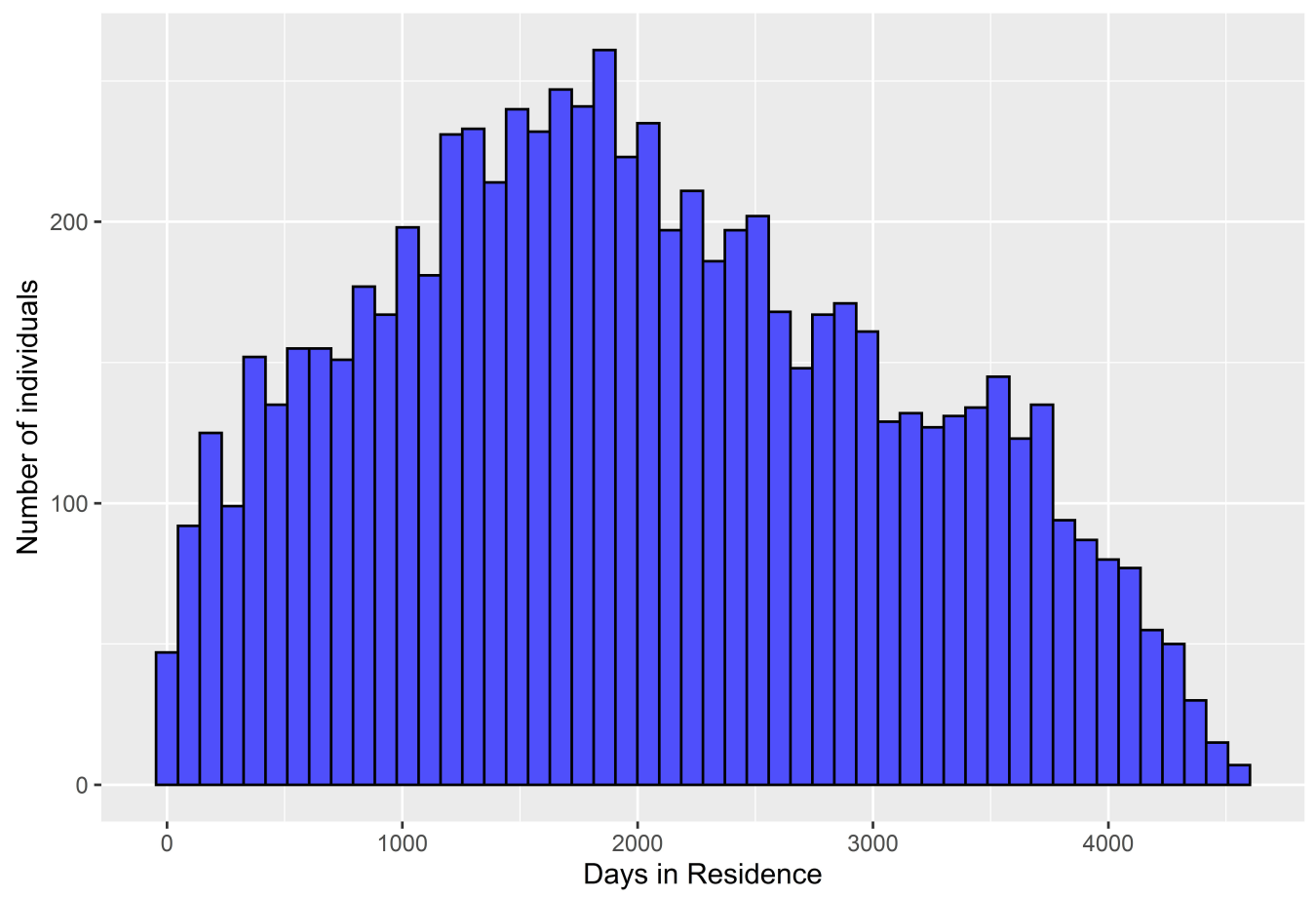

Table 6 presents the results of two very simple models that summarise the relationship between time in residence and subjective well-being. Models are presented for time in residence measured in years and in days, with controls for positive affect and structure price included. The estimated parameters imply that the evolution of SWB over time declines slightly for the first 2-3 years of residence, rising sharply after 929 days in residence. This seems in line with other known processes of social capital accumulation and is at least consistent with the pathways we suggest through which SWB might play an important role in the analysis of house prices.

\section{Ordinary least squares}

Table 7 presents the results of our model estimates. We combine all estimation approaches in a single table to facilitate comparison between estimation approaches and model specifications. Nested model specifications estimated using OLS are presented in columns 2 through 4. These are followed in columns 5 and 6 by models estimated using an instrumental variables approach to account for potential endogeneity of measured SWB. Finally in columns 7 and 8 we present alternative 
Table 6: Subjective well-being and time in residence

\begin{tabular}{ccc} 
Coefficients: & Years & Days \\
\hline Constant & $2.8497^{* * *}$ & $2.8530^{* * *}$ \\
$\sigma$ & 0.0522 & 0.0547 \\
$\operatorname{Ln}($ Affect +1$)$ & $0.7642^{* * *}$ & $0.7710^{* * *}$ \\
$\sigma$ & 0.0167 & 0.0173 \\
$\operatorname{Ln}($ Price $)$ & $0.0294^{* * *}$ & $0.0284^{* * *}$ \\
$\sigma$ & 0.0039 & 0.0041 \\
$\operatorname{TiR}$ & $-1.4867 \times 10^{-3}$ & $-5.5870 \times 10^{-6}$ \\
$\sigma$ & $1.5609 \times 10^{-3}$ & $5.7080 \times 10^{-6}$ \\
$\mathrm{TiR}^{2}$ & $3.5530 \times 10^{-4 * *}$ & $3.0070 \times 10^{-9 * *}$ \\
$\sigma$ & $1.4390 \times 10^{-4}$ & $1.3180 \times 10^{-9}$ \\
& & \\
$F(4,14852)$ & $562.7^{* * *}$ & $527.6 * * *$ \\
$R S E$ & 0.1931 & 0.1943 \\
$R^{2}$ & 0.1316 & 0.1943 \\
$\bar{R}^{2}$ & 0.1314 & 0.1324 \\
\hline$* * *-\mathrm{p}<0.001, * *$ & $\mathrm{p}<0.01, *-\mathrm{p}<0.05, \dagger-\mathrm{p}<0.10$
\end{tabular}

spatial econometric approaches to account for spatially correlated errors, spatial autoregressive structures, and spatially lagged effects of subjective well-being. The dependent variable in all models is the log of the transaction price. 
Table 7: Hedonic model estimates

Variable

Well-being

$\sigma$

Lag well-being $(\theta)$

$\sigma$

Positive affect

$\sigma$

$\rho$ (spatial error dependence)

$\sigma$

$\lambda$ (spatial autocorrelation)

$\sigma$

$\operatorname{Ln}($ Urban distance $)$

$\sigma$

$\stackrel{N}{\omega}$
Behavioural and Subjective Characteristics

$\begin{array}{llccc}0.0385^{* * *} & 0.181^{* * *} & 0.1744^{* * *} & 0.0893^{* * *} & 0.1149^{* * *} \\ 0.009 & 0.029 & 0.026 & 0.018 & 0.023 \\ & & & 0.1007^{* *} & \\ & & & 0.035 & \\ 0.1018^{* * *} & -0.0077 & -0.0027 & 0.0321 & 0.0094 \\ 0.02 & 0.029 & 0.028 & 0.021 & 0.024 \\ & & & 0.4282^{* * *} & 0.4238^{* * *} \\ & & & 0.012 & 0.012 \\ & & & 0.2409^{* * *} & 0.2445^{* * *} \\ & & & 0.012 & 0.012\end{array}$

neighbourhood and Environmental Characteristics

\begin{tabular}{cccccc}
$-0.0053^{*}$ & $-0.0055^{*}$ & $-0.0058^{*}$ & $-0.0058^{*}$ & $-0.0119^{* * *}$ & $-0.0116^{* * *}$ \\
0.002 & 0.002 & 0.002 & 0.002 & 0.003 & 0.003 \\
$0.1008^{* * *}$ & $0.1006^{* * *}$ & $0.1003^{* * *}$ & $0.1003^{* * *}$ & $0.0859^{* * *}$ & $0.0859^{* * *}$ \\
0.005 & 0.005 & 0.005 & 0.005 & 0.007 & 0.007 \\
$-0.1536^{* * *}$ & $-0.1535^{* * *}$ & $-0.1531^{* * *}$ & $-0.1531^{* * *}$ & $-0.1164^{* * *}$ & $-0.1159^{* * *}$ \\
0.009 & 0.009 & 0.009 & 0.009 & 0.013 & 0.013 \\
$-0.0185^{* * *}$ & $-0.0182^{* * *}$ & $-0.0171^{* *}$ & $-0.0172^{* *}$ & -0.0118 & -0.012 \\
0.005 & 0.005 & 0.005 & 0.005 & 0.008 & 0.008 \\
$-0.0087^{* * *}$ & $-0.0087^{* * *}$ & $-0.0088^{* * *}$ & $-0.0088^{* * *}$ & $-0.0116^{* * *}$ & $-0.0115^{* * *}$ \\
0.002 & 0.002 & 0.002 & 0.002 & 0.002 & 0.002 \\
$-0.0045^{*}$ & $-0.0043^{*}$ & $-0.0038^{*}$ & $-0.0039^{*}$ & -0.0039 & $-0.004 \dagger$ \\
0.002 & 0.002 & 0.002 & 0.002 & 0.002 & 0.002 \\
$-0.0553^{* * *}$ & $-0.0549^{* * *}$ & $-0.0546^{* * *}$ & $-0.0547^{* * *}$ & $-0.0357^{* * *}$ & $-0.0359^{* * *}$ \\
0.003 & 0.003 & 0.003 & 0.003 & 0.004 & 0.004 \\
$0.6508^{* * *}$ & $0.6485^{* * *}$ & $0.6471^{* * *}$ & $0.6471^{* * *}$ & $0.5932^{* * *}$ & $0.5931^{* * *}$ \\
0.009 & 0.009 & 0.009 & 0.009 & 0.008 & 0.008 \\
$0.0514^{* * *}$ & $0.0514^{* * *}$ & $0.0514^{* * *}$ & $0.0514^{* * *}$ & $0.0553^{* * *}$ & $0.0552^{* * *}$ \\
0.001 & 0.001 & 0.001 & 0.001 & 0.001 & 0.001 \\
\hline $0.001, * *-\mathrm{p}<0.01, *-\mathrm{p}<0.05, \dagger-\mathrm{p}<0.10$ & & &
\end{tabular}

Continued on next page 
... continued from previous page:

\begin{tabular}{|c|c|c|c|c|c|c|c|}
\hline Variable & OLS Model 1 & OLS Model 2 & OLS Model 3 & IV Health & IV Health/Pain & GNS & SAC \\
\hline Rooms & $0.0309 * * *$ & $0.0327^{* * *}$ & $0.0326 * * *$ & $0.0323 * * *$ & $0.0323 * * *$ & $0.0498 * * *$ & $0.05^{* * *}$ \\
\hline$\sigma$ & 0.009 & 0.009 & 0.009 & 0.009 & 0.009 & 0.008 & 0.008 \\
\hline$\sigma$ & 0.008 & 0.008 & 0.008 & 0.008 & 0.008 & 0.007 & 0.007 \\
\hline Three Bathrooms & $0.2432 * * *$ & $0.2489 * * *$ & $0.2487 * * *$ & $0.2542 * * *$ & $0.254 * * *$ & $0.1801^{* * *}$ & $0.1806 * * *$ \\
\hline$\sigma$ & 0.006 & 0.006 & 0.006 & 0.006 & 0.006 & 0.005 & 0.005 \\
\hline Parking & $0.1244 * * *$ & $0.1342 * * *$ & $0.1338 * * *$ & $0.1327^{* * *}$ & $0.1327^{* * *}$ & $0.1203 * * *$ & $0.1205^{* * *}$ \\
\hline$\sigma$ & 0.004 & 0.004 & 0.004 & 0.004 & 0.004 & 0.004 & 0.004 \\
\hline Basement & $-0.0192^{*}$ & $-0.0228 * *$ & $-0.0227^{* *}$ & $-0.0223^{* *}$ & $-0.0223 * *$ & $-0.032 * * *$ & $-0.0319 * * *$ \\
\hline$\sigma$ & 0.008 & 0.008 & 0.008 & 0.008 & 0.008 & 0.007 & 0.007 \\
\hline Listed & $0.2465^{* * *}$ & $0.2313^{* * *}$ & $0.2287 * * *$ & $0.2257^{* * *}$ & $0.2258 * * *$ & $0.1899 * * *$ & $0.1895 * * *$ \\
\hline$\sigma$ & 0.029 & 0.028 & 0.028 & 0.028 & 0.028 & 0.025 & 0.025 \\
\hline Monument & $0.1416 * * *$ & $0.1425 * * *$ & $0.14^{* * *}$ & $0.1418 * * *$ & $0.1418 * * *$ & $0.1648 * * *$ & $0.1648 * * *$ \\
\hline$\sigma$ & 0.024 & 0.023 & 0.023 & 0.023 & 0.023 & 0.02 & 0.02 \\
\hline Constant & $8.3239 * * *$ & $8.5819 * * *$ & $8.271 * * *$ & $7.8333 * * *$ & $7.8533 * * *$ & $4.8285^{* * *}$ & $5.1519 * * *$ \\
\hline$\sigma$ & 0.072 & 0.079 & 0.088 & 0.122 & 0.117 & 0.242 & 0.185 \\
\hline
\end{tabular}

\begin{abstract}
0.072
\end{abstract}
Int/Exterior maintenance Insulation level

Construction Period

Year of sale

$\begin{array}{cc}\text { Yes } & \text { Yes } \\ \text { Yes } & \text { Yes } \\ \text { Yes } & \text { Yes } \\ \text { Yes } & \text { Yes }\end{array}$

$* * *-p<0.001, * *-p<0.01, *-p<0.05, \dagger-p<0.10$

\begin{tabular}{lcccc}
\multicolumn{2}{c}{ Other variables in models } & \\
Yes & Yes & Yes & Yes & Yes \\
Yes & Yes & Yes & Yes & Yes \\
Yes & Yes & Yes & Yes & Yes \\
Yes & Yes & Yes & Yes & Yes
\end{tabular}


... continued from previous page:

\begin{tabular}{|c|c|c|c|c|c|c|c|}
\hline Variable & OLS Model 1 & OLS Model 2 & OLS Model 3 & IV Health & IV Health/Pain & GNS & SAC \\
\hline & \multicolumn{7}{|c|}{ Measures of model fit to data } \\
\hline Residual $\sigma$ & 0.2247 & 0.2175 & 0.217 & 0.2187 & 0.2186 & & \\
\hline $\bar{R}^{2}$ & 0.7024 & 0.7212 & 0.7224 & 0.7179 & 0.7183 & & \\
\hline $\mathrm{AIC}$ & -2150.58 & -3109.98 & -3172.68 & & & & \\
\hline$F$ & $662.7^{* * *}$ & $641.4^{* * *}$ & $624.5^{* * *}$ & & & & \\
\hline Wald test & & & & $615^{* * *}$ & $615.9 * * *$ & & \\
\hline Weak instruments & & & & $1744.71^{* * *}$ & $1057.375 * * *$ & & \\
\hline Wu-Hausman & & & & $28.05^{* * *}$ & $30.969 * * *$ & & \\
\hline \multirow[t]{2}{*}{ Sargan } & & & & & 0.332 & & \\
\hline & \multicolumn{7}{|c|}{ Tests for spatial dependence and autocorrelation } \\
\hline \multirow[t]{2}{*}{ Moran's $I$} & & & & & & $55.294 * * *$ & $54.548^{* * *}$ \\
\hline & \multicolumn{7}{|c|}{ Partial first stage results for well-being instruments } \\
\hline $\operatorname{Ln}($ Health +1$)$ & & & & $0.1723 * * *$ & $0.1723 * * *$ & $0.1723^{* * *}$ & \\
\hline$\sigma$ & & & & 0.006 & 0.006 & 0.006 & \\
\hline $\operatorname{Ln}($ Pain +1$)$ & & & & & $0.0807^{* * *}$ & $0.0807 * * *$ & \\
\hline$\sigma$ & & & & & 0.005 & 0.005 & \\
\hline
\end{tabular}

${ }^{* * *}-\mathrm{p}<0.001,{ }^{* *}-\mathrm{p}<0.01,{ }^{*}-\mathrm{p}<0.05, \dagger-\mathrm{p}<0.10$ 
OLS Model 1 presents estimates that include only structure characteristics. The estimated parameters are largely as would be expected. A one per cent change in floorspace is associated with a 0.65 to 0.66 percent increase in the transaction price. A one percent change in lot size increases the transaction price by 0.05 per cent. The number of rooms, and availability of bathrooms, balconies, and parking are all associated with an increase in the transaction price.

The presence of an attic, basement, and under-roof storage area are associated with lower transaction prices. The data for usable interior surface area as described in NVM and VBO and VastgoedPRO and Vereniging Nederlandse Gemeenten and Waarderingskamer (2018) specify that floorspace (floorm2) includes all usable area, which includes basements, attics, and under-roof storage. The negative coefficients estimates arise from a portion of the interior area not being part of the living area. Listed buildings (monuments) are more valuable than those that are not listed, and for non-monuments, a monumental appearance leads to a smaller increase in price. Higher levels of interior and exterior maintenance are associated with higher transaction prices, and similarly higher levels of insulation are associated with higher transaction prices, although buildings with only one layer of insulation appear to sell for less than those with no insulation (reference group). Structures from the 1980's attract the lowest transaction prices.

OLS Model 2 adds the neighbourhood characteristics. Increases in density are associated with increases in transaction price, which is consistent with the standard urban land use model presented in Alonso (1964). Controlling for that, larger distances to an urban center (as a proxy for labor market access) are associated with lower transaction prices, burglaries are associated with lower transaction prices, as is ethnic diversity.

OLS Model 3 includes subjective well-being and positive affect. Both coefficients are significant and positively related to transaction price. This supports our hypothesis that higher transaction prices are associated with higher derived utility from living in a house and location, which can be measured using subjective well-being. In addition, this model shows that positive affect is associated with a higher transaction price, which supports the optimistic buyer hypothesis. The AIC's for these three models suggest that the fully specified model is the preferred one, decreasing from $-2,151$ for the property characteristics model, to $-3,110$ for the model including neighbourhood characteristics, and finally $-3,173$ for the model including subjective well-being.

The inclusion of subjective well-being in model 3 is associated with a number of small changes to the parameter estimates for the usual variables included in a hedonic price model (model 2). The parameter estimate for floorspace, for example, decreases by 0.0023 , equivalent to 0.26 of the standard error of the parameter estimate. This suggests that the parameter estimate in the standard hedonic is slightly biased upwards, meaning that some part of the increased willingness to pay attributed to a larger floor area is actually due to the omitted attributes proxied through subjective well-being. We note a similar change in the coefficients for the distance to forests and the distance to nature: the negative association in both coefficients decreases when subjective well-being is included in the model. This indicates that part of the willingness to pay attributed to proximity to nature is potentially due to some other unobserved characteristic associated with occupant subjective well-being.

Similar to Anselin and Lozano-Gracia (2008) we test for spatial dependence in our data, and find robust Lagrange Multipliers in excess of 3,511 for spatial dependence in the error term, and greater than 177 for spatial dependence in the 
dependent term. These indicate that we need to control for spatial dependence in the dependent and for spatial dependence in the error (a spatial autoregressive combined model).

\section{Endogeneity and IV estimation}

Columns 5 and 6 of Table 7 present estimates of the fully specified model using an instrumental variables approach with self-reported health as an instrument for the potentially endogenous subjective well-being variable. Diagnostic statistics indicate that SWB is significantly endogenous with the transaction price, with the Wu-Hausman being highly significant at $p<0.001$. Instrumenting for subjective well-being leaves the sign and significance of most of the coefficients intact, with the exception of positive affect whose presence as a control for temporal mood is not of central interest to our analysis. The results indicate that self-reported health is a strong instrument for subjective well-being (weak instruments $p<0.001$ ). This suggests that the differences in parameter estimates relative to the OLS models (particularly noticeable for SWB and positive affect) may be due to endogeneity bias in the OLS estimates. Partial results from first stage regressions for both self-reported health status and self-reported experience of pain as instruments are provided in the final four lines of the table.

In order to test for overidentifying restrictions we add a second instrumental variable, self reported pain, and rerun the regression. The resulting Sargan test score has a p-value of 0.33 , which means we accept that the instruments self-reported health and self-reported pain are not correlated with the error term. The estimated r-squared results for the IV regressions are lower than those for the OLS, a familiar feature when using instrumental variables, although the change is modest.

The coefficients for the IV regression with self-reported health and pain instruments show that SWB is significantly positively related to transaction price. The coefficient is similar for both IV specifications, indicating that an increase in subjective well-being of 1 percent is associated with a $0.18-0.174$ per cent increase in transaction price. Although the novelty of our estimates means any comparison must be tentative, the size of this coefficient seems plausible given that subjective well-being is capturing a range of structure and neighbourhood amenities that are unobserved.

We find similar biases in the IV Health/Pain model compared to OLS model 2 as we did in OLS model 3 . The size of the changes is somewhat larger. Expressed in standard errors of the coefficients in model 2, the estimated willingness to pay for floor area is down 0.41 standard error, and distances to nature and forests are down 0.2 and 0.3 standard errors respectively.

\section{Spatial models}

The robust Lagrange multiplier tests presented in columns 2 through 4 for the OLS models suggest that the primary dependence problem is associated with the error term, but also indicate the presence of spatial auto-correlation in the dependent variable. From our theoretical model, we suspect that we might find a spatial lag in the independent variables as suggested in Vega and Elhorst (2015), serving as a proxy for unobservable neighbourhood effects. To address this, we first calculate a spatially lagged variable of subjective well-being (inverse euclidean distance, 1 kilometer bandwidth) and add this to the spatial models. The first model we estimate is, therefore, a generalised methods of moments instrumental variables version of the General Nesting Specification (GNS), where we restrict the lagged X-variables to SWB. The GNS model can be reduced to a Spatial Autoregressive Combined model (SAC) if the spatial autocorrelation coefficient $(\lambda)$ is not significant 
(see table 7).

The GNS model presented in the penultimate column of table 7 indicates that the lagged SWB variable is positively related to the transaction price, with a coefficient of just over 0.10 . This is consistent with the expectation that higher regional utility is associated with higher transaction prices. The size of the coefficient for subjective well-being has decreased relative to the specification without the lagged subjective well-being variable. For completeness the Spatial Error specification is also reported in the final column of table 7.

In the SAC specification in the final column of table 7, we observe a smaller coefficient for the direct effect of subjective well-being on the transaction price (0.1149) than reported in the non-spatial IV estimates. This result indicates that a model specification without allowing for spatial structure in the error terms leads to an overestimation of the effect of subjective well-being. In both the SAC model and the GNS model we find similarly sized significant contributions of subjective wellbeing, and the precision with which the effect of SWB on the transaction price is measured (standard error) stays relatively constant for all the instrumental variables regressions (between 0.020 and 0.023 ). We calculate an approximation of model r-squared by correlating the predicted and observed transaction prices. For the GNS specification this gives 0.7574 and for the SAC specification 0.7568 , indicating reasonably high explained variances, considering no property or regional level fixed effects could be added.

Comparing the coefficients between OLS model 2 and the spatial IV models, we find substantial differences in the parameter estimates for the conventional variables in the hedonic price model. For floorspace, the parameter estimate is down to 0.59 , a differences of 0.06 or 6.4 standard errors lower than in OLS model 2. Lot size, on the other hand, is up by 3.9 standard errors (from 0.051 to 0.054 ). We also see some larger differences among the variables that are based on distance functions (e.g. distance to water or forests, distance to urban centres). This is to be expected, as these are by definition spatially autocorrelated. One other notable change is the burglary rate, which is significant and negative in the instrumental variable models. In the spatial models it remains negative but the estimate is so imprecise that we cannot be confident that the true effect is other than zero. A substantial part of the changes in coefficients for the conventional variables will be attributable to the inclusion of a spatial autoregressive term for the dependent variable. However, the previous comparisons using only the OLS models 2 and 3, and the IV Health/Pain model show that the inclusion of the subjective well-being term can both substantially improve model estimates (evidenced in the AIC's) as well as reduce bias in variable conventionally found in hedonic price models.

Figure 3 shows the residuals from the first stage estimation of the GNS model. Compared to the outcome variable, we see that there is a good fit for the first stage estimation at the higher levels of subjective well-being. As is common in SWB measurement, fewer people give lower scores for their well-being, meaning the first stage regression can not be estimated with the same level of precision. At the higher end of the scale, we see that the first stage estimates exceed the maximum theoretical value of the subjective well-being scale. This is likely to be the result of a ceiling effect observed in other self-report well-being and health scales, where beyond a certain level of happiness marginal gains can no longer be registered in the survey. Given the lower numbers of respondents involved in the problems at the lower end of the distribution and at the higher end of the distribution, we believe these deviations are unlikely to have much leverage for shifting the 
Figure 3: Residuals from instrument estimate of $\operatorname{Ln}($ well-being)

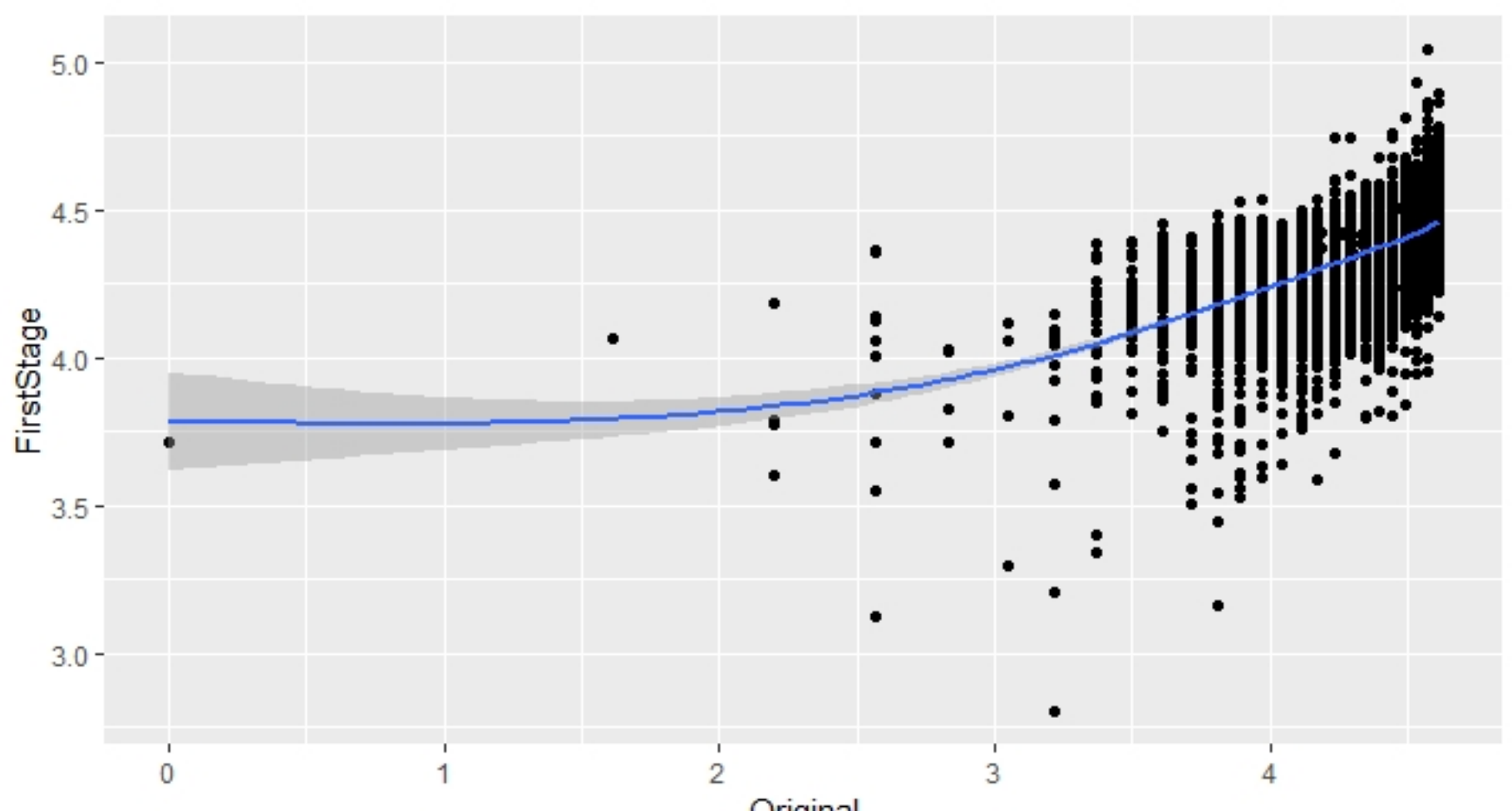

Original

coefficients for subjective well-being.

We check for spatial autocorrelation in the residuals using Moran's I, and find that this remains an issue. The results from both spatial model specifications contain significant residual spatial autocorrelation, with the statistic relatively similar for the GNS and SAC models. The residual maps are displayed in Figure 4 and give an indication of the location of the spatial autocorrelation. Given the cross-sectional nature of our data, the usual approach of region fixed effects is not an option. The locations of the high and low residuals do make some intuitive sense, considering some background characteristics of the North of the Netherlands. The main low cluster towards the east of the study region corresponds with the Veenkoloniën and Oldambt areas, which have a history of difficult economic development, and relatively low levels of in-migration, as discussed in Rijnks and Strijker (2013) and Thissen et al. (2010). Similarly, at the time of measurement, the in the northern regions of the mainland, a shift towards population decline and demographic ageing was starting (Haartsen and Venhorst, 2010). The finding that house values are depressed somewhat in these regions is not surprising, and might be remedied by a regional fixed effects specification if dynamic data were available. The smaller clusters of positive residuals correspond with smaller urban regions, indicating that there is perhaps a non-linearity to the effect of population density or labor market opportunity. Up to a five degree polynomial for population density was added to the model to correct for this. This did not resolve the issue, perhaps because the effect does not appear to be general across all smaller urban areas. This indicates that some unobserved regional effect or interaction, specific to some but not all smaller urban areas, remains.

Over the sample period of 2000 to 2012, the pattern of house prices estimated by the GNS or IV hedonic models produces a price index that closely matches the CBS house price index for the north of the Netherlands. Figure 5 presents three house price indices together. 
Figure 4: Residual maps for selected models

OLS (FULL)

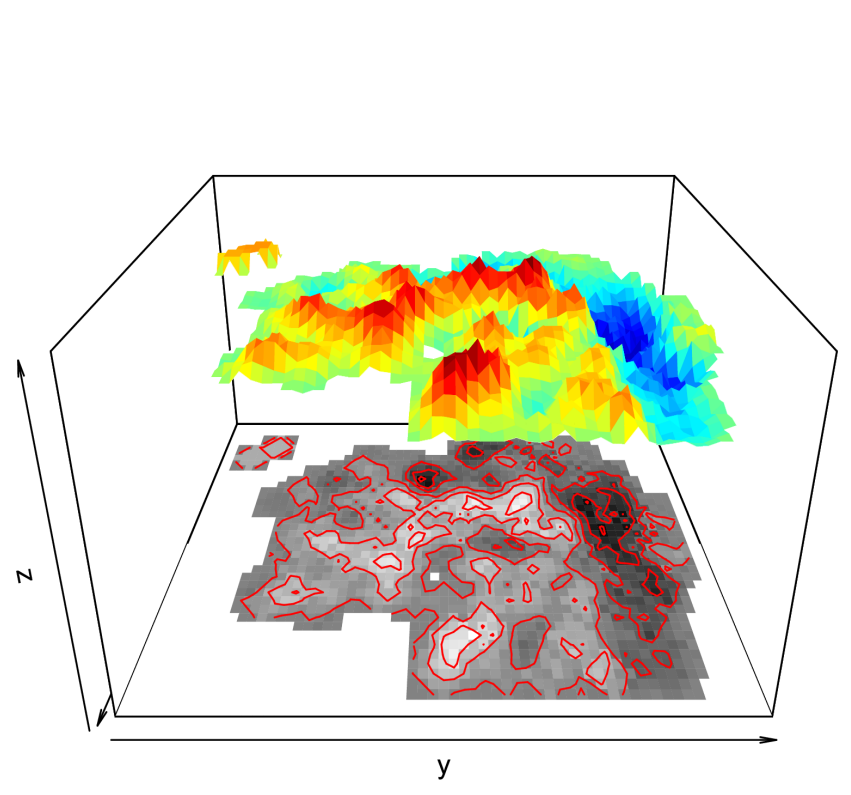

Spatial Durbin Error

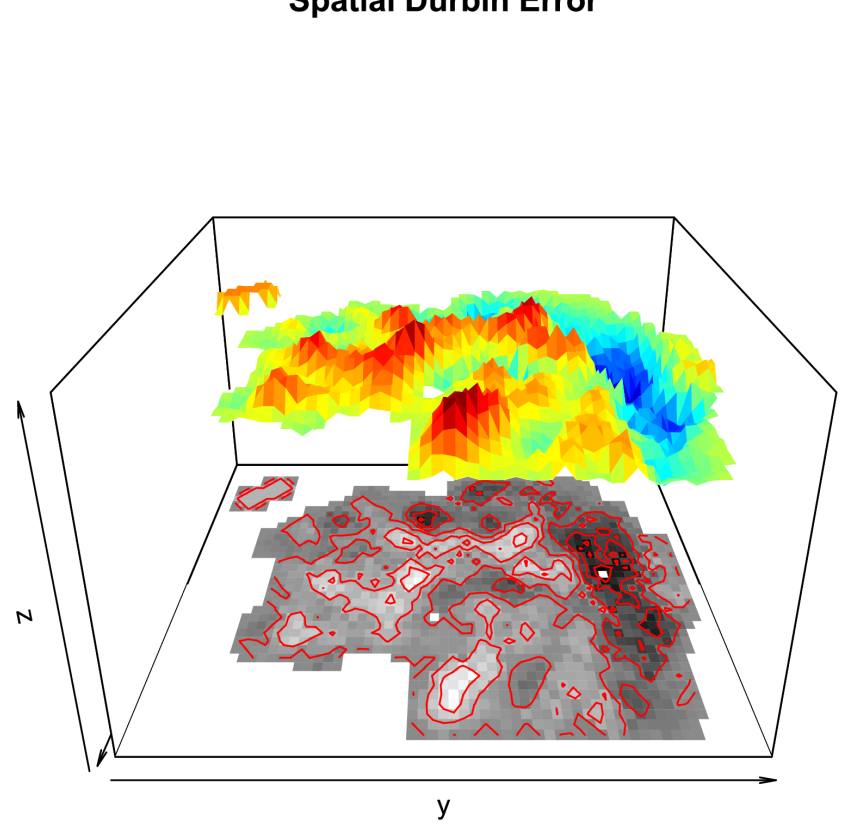

IV Health Pain

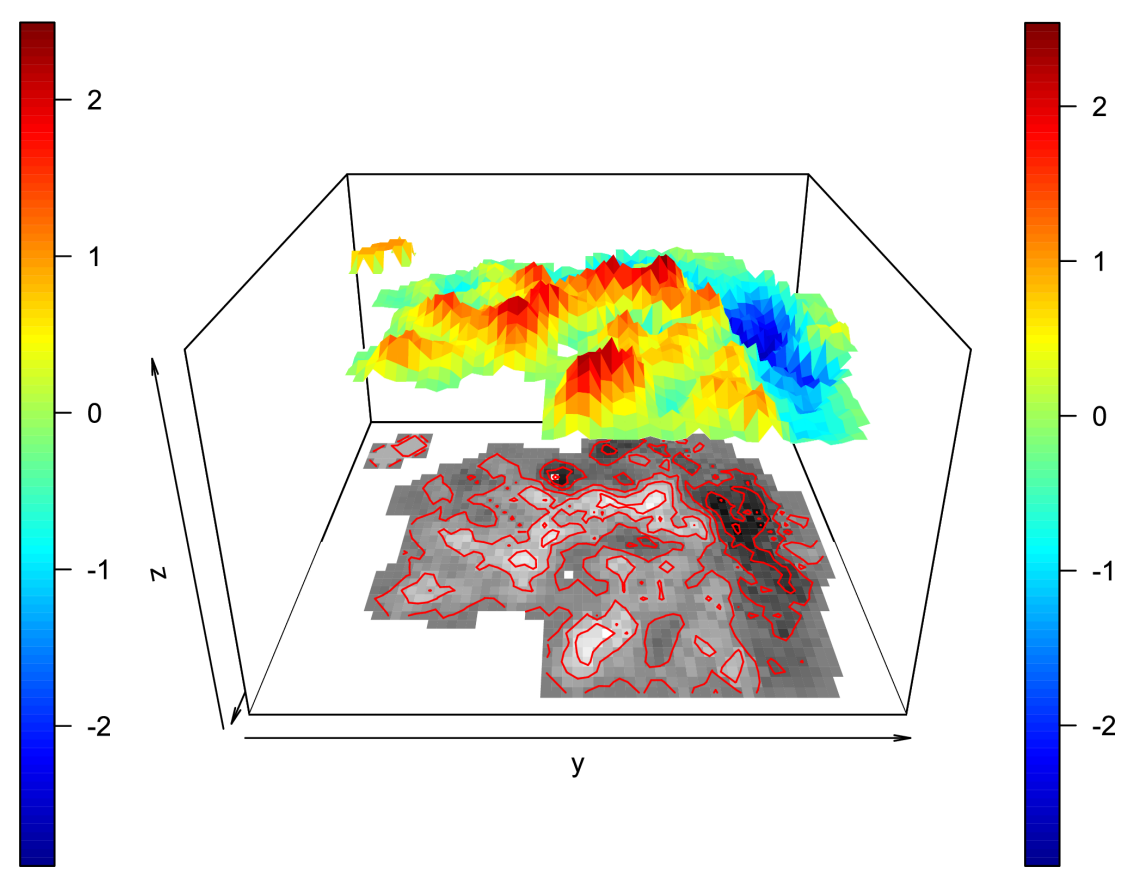

Spatial Error

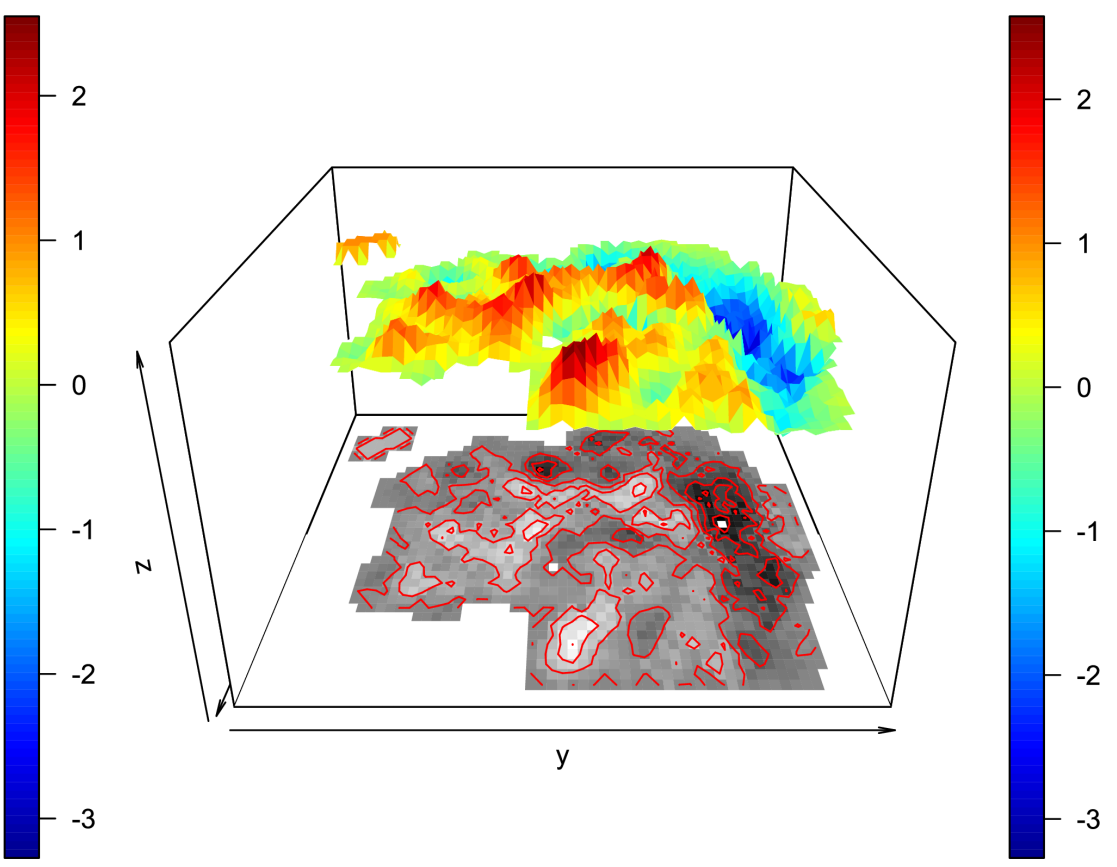


Figure 5: Indices implied by model estimates compared with CBS repeat sales index for the north of the Netherlands

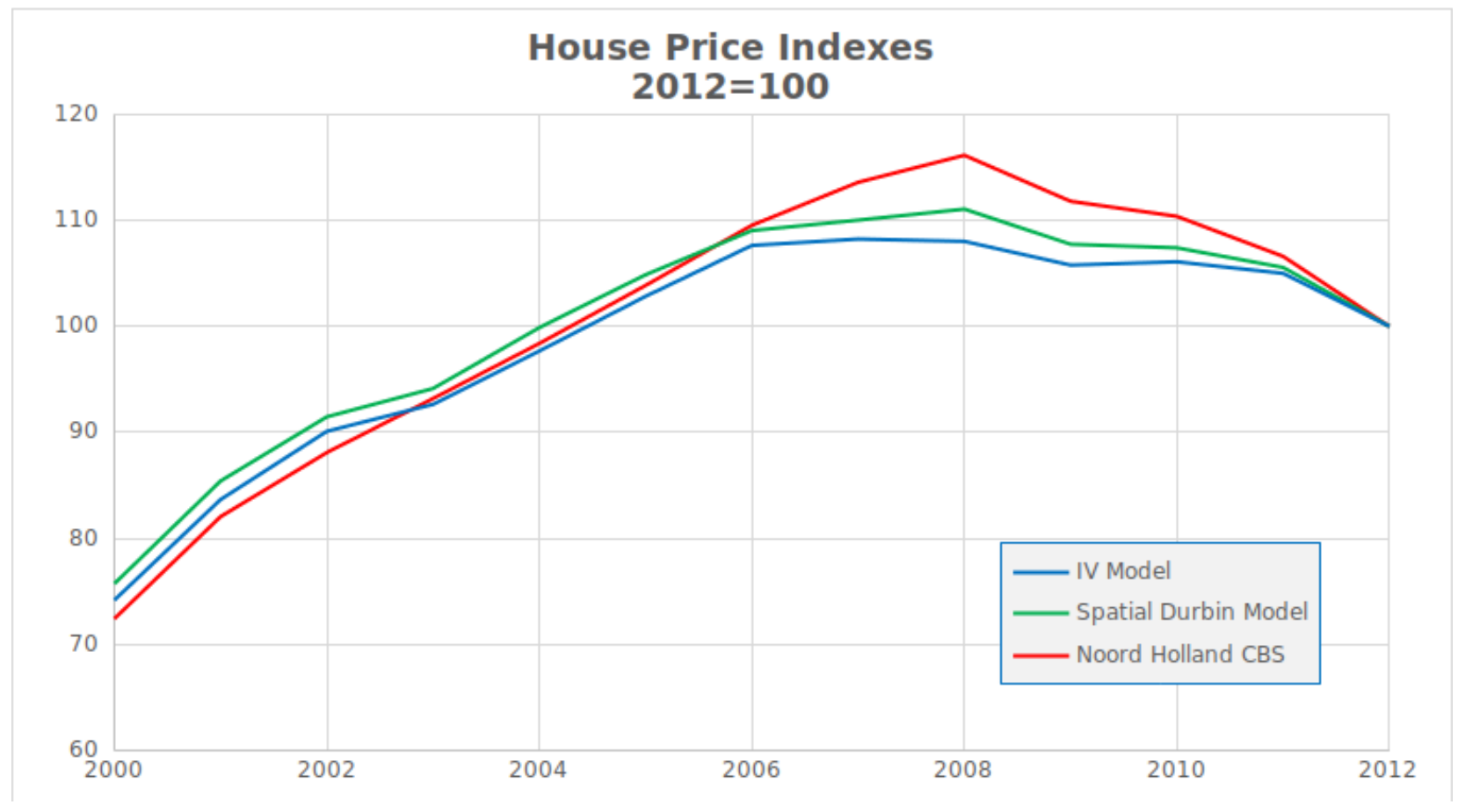

The GNS model hits a peak in 2008, similar to (but slightly lower than) the CBS model. The IV model generates a price index that peaks in 2007. Overall, this confirms both the representativeness of our sample and the performance of our estimates noted above.

\section{Conclusion and Discussion}

This paper aims to establish a connection between house transaction prices and subjective well-being measures, used as a proxy for both unobserved house characteristics and unobserved neighbourhood characteristics. The unobservability of characteristics is one of the main problems facing housing market researchers. The extent of these problems ranges from not being able to identify property level characteristics (e.g. interior arrangement, curb appeal), as well as regional characteristics (e.g. subtle differences between amenities such as expensive versus low-cost supermarkets). This unobservability can stem from a lack of data, or from the unobservable characteristics emerging after the sale, such as friendliness of the neighbors. Recent progress in happiness research, for example Diener and Suh (1997) or Veenhoven (2012), shows that a measure of happiness might be usefully employed to estimate utility. This paper aims to combine progress in the literature surrounding happiness with hedonic modelling, using subjective well-being as a proxy measure for utility derived from unobservables at the house or regional levels.

We find that subjective well-being is significantly and positively correlated with transaction prices, after correcting for a large number of known correlates. Using instrumental variables regressions we show that the subjective well-being of the owner/occupier is endogenous with the transaction price paid for the property. Instrumenting using self-reported health and pain allows us to get a consistent estimate for the estimates. A one per cent increase in subjective well-being corresponds to 
an approximately 0.18 per cent increase in transaction price. This effect is consistent with what would be expected from the literature linking subjective well-being with utility, and in size is within a plausible range. The relationship between subjective well-being and transaction price remains positive and significant when estimated using the explicit spatial two stage least squares regression detailed in Kelejian and Prucha (2010). The association between subjective well-being and property prices remains positive and significant when spatially lagged values of subjective well-being are included in the model, although the size of the coefficient decreases. When separated, the effect of higher subjective well-being in the neighbourhood is slightly larger than the individual effect, at 0.10 and 0.09 respectively. The relation shows that measured utility is positively associated with transaction price both at the individual house or household level, and at the regional level.

In our results, we are able to compare more conventional hedonic price models with those including subjective well-being, IV specifications and spatial IV specifications. We find indicate that the parameter estimates for positive characteristics (e.g. floor-space) are biased upwards, while for negative characteristics (e.g. distance to amenities) they are biased downwards. This suggests that willingness to pay for housing characteristics are overestimated. The model diagnostics improve with the inclusion of subjective well-being in the regressions. Linking back to the literature on a spatial equilibrium of utility, we find that higher SWB both individually and in the neighbourhood are indeed related to higher transaction values. Regional variations in utility are translated into higher rents, and in turn a move towards spatial equilibrium (see Goetzke and Islam, 2017; Ballas and Tranmer, 2012). Additionally, the outcomes from this study reveal that subjective well-being indicators can be usefully employed to estimate the impact on price of unobserved characteristics using hedonic pricing models. Although subjective well-being combined with individual property data is not widely available, small scale regional subjective well-being data is increasingly becoming part of the set of commonly collected statistics (Frey and Stutzer, 2005). Our estimates show that small-scale regional subjective well-being data alone will improve model estimation, even in lieu of individual subjective well-being data. The results in this paper argue for the careful consideration of any available subjective well-being data, by practitioners as well as academics with an interest in property valuation. Finally, these results provide justification for including subjective well-being as part of a standardized data collection strategy for housing data.

On a conceptual level, the models estimated here add to the plausibility of subjective well-being as a measure of in situ utility. The coefficients estimated in the models are positive and significant, both for the direct effect as well as the spatially lagged effect of subjective well-being. The results are consistent with the hypothesis that motivates this paper and that almost every house buyer or estate agent understands: there are unobserved and difficult-to-measure attributes of structure, neighbourhood, and community that affect the utility of a house or residential location. While these factors do not show up in the usual property data, they affect the willingness-to-pay of a buyer after inspection of the house, or the price that must be paid to induce a resident to sell the house and relocate. Our study provides the first estimates of the importance of these effects. 


\section{References}

Abbott, J. K. and Klaiber, H. A. (2011). An embarrassment of riches: Confronting omitted variable bias and multiscale capitalization in hedonic price models. The Review of Economics and Statistics, 93(4):1331 - 1342.

Alonso, W. (1964). Location and Land Use, Toward a General Theory of Land Rent. Harvard University Press, Berlin, Boston.

Anselin, L. and Lozano-Gracia, N. (2008). Errors in variables and spatial effects in hedonic house price models of ambient air quality. Empirical Economics, 34:5-34.

Atalay, K., Edwards, R., and Liu, B. Y. (2017). Effects of house prices on health: New evidence from australia. Social Science \& Medicine, 192:36 - 48.

Bajari, P. and Benkard, C. L. (2005). Demand estimation with heterogeneous consumers and unobserved product characteristics: A hedonic approach. Journal of Political Economy, 113(6):1239-1276.

Ballas, D. and Tranmer, M. (2012). Happy people or happy places? a multilevel modeling approach to the analysis of happiness and well-being. International Regional Science Review, 35(1):70-102.

Billé, A. G., Benedetti, R., and Postiglione, P. (2017). A two-step approach to account for unobserved spatial heterogeneity. Spatial Economic Analysis, 12(4):452-471.

Bivand, R. and Wong, D. W. S. (2018). Comparing implementations of global and local indicators of spatial association. TEST, 27(3):716-748.

Bivand, R. S., Pebesma, E., and Gomez-Rubio, V. (2013). Applied spatial data analysis with R, Second edition. Springer, NY.

Bockstael, N. E. and McConnell, K. E. (2007). Environmental and Resource Valuation with Revealed Preferences. Springer, P.O.Box 17, 3300 AA, Dordrecht, The Netherlands.

Brounen, D. and Kok, N. (2011). On the economics of energy labels in the housing market. Journal of Environmental Economics and Management, 62(2):166 - 179.

Cattaneo, M. D., Galiani, S., Gertler, P. J., Martinez, S., and Titiunik, R. (2009). Housing, health, and happiness. American Economic Journal: Economic Policy, 1(1):75 - 105.

Cheshire, P. and Sheppard, S. (2004). Introduction to feature: The price of access to better neighbourhoods. The Economic Journal, 114(499):391 - 396.

Clark, A. and Díaz Serrano, L. (2020). The long-run effects of housing on well-being. Working papers, Universitat Rovira i Virgili, Department of Economics. 
Crawford, J. R. and Henry, J. D. (2004). The positive and negative affect schedule (panas): Construct validity, measurement properties and normative data in a large non-clinical sample. British Journal of Clinical Psychology, 43(3):245-265.

Debrezion, G., Pels, E., and Rietveld, P. (2011). The impact of rail transport on real estate prices: An empirical analysis of the dutch housing market. Urban Studies, 48(5):997-1015.

Dickerson, A., Hole, A. R., and Munford, L. A. (2014). The relationship between well-being and commuting revisited: Does the choice of methodology matter?. Regional Science and Urban Economics, 49:321 - 329.

Diener, E. and Suh, E. (1997). Measuring quality of life: Economic, social, and subjective indicators. Social Indicators Research, 40(1):189-216.

Diener, E., Suh, E. M., Lucas, R. E., and Smith, H. L. (1999). Subjective well-being: Three decades of progress. Psychological Bulletin, 125(2):276-302.

DiPasquale, D. and Glaeser, E. L. (1999). Incentives and social capital: Are homeowners better citizens? Journal of Urban Economics, 45:354 - 384.

Dutch National Statistics (CBS) (2018a). Begrippen.

Dutch National Statistics (CBS) (2018b). Existing properties; region; transaction prices; price-index $2010=100$ (cbs; bestaande koopwoningen; regio; verkoopprijzen; prijsindex $2010=100$.

Easterlin, R. A. (1974). Does economic growth improve the human lot? some empirical evidence. Nations and households in economic growth, 89:89-125.

Elhorst, J. P. (2014). Spatial Econometrics. Springer Berlin Heidelberg, Berlin, Heidelberg.

Ferreira, S. and Moro, M. (2010). On the use of subjective well-being data for environmental valuation. Environmental and Resource Economics, 46(3):249 - 273.

Fichera, E. and Gathergood, J. (2016). Do wealth shocks affect health? new evidence from the housing boom. Health Economics, 25(S2):57-69.

Fleming, D., Grimes, A., Lebreton, L., Maré, D., and Nunns, P. (2018). Valuing sunshine. Regional Science and Urban Economics, 68:268-276.

Folmer, H., Suparman, Y., and Oud, J. (2014). Hedonic price models with omitted variables and measurement errors: A constrained autoregression - structural equation modeling approach with application to urban indonesia. Journal of Geographical Systems, 16(1):49-70.

Foye, C. (2017). The relationship between size of living space and subjective well-being. Journal of Happiness Studies, 18(2):427-461. 
Frey, B. S. and Stutzer, A. (2002). What can economists learn from happiness research? Journal of Economic Literature, 40(2):402 - 435.

Frey, B. S. and Stutzer, A. (2005). Beyond outcomes: Measuring procedural utility. Oxford Economic Papers, 57(1):90 111.

Fu, S. (2005). What has been capitalized into property values: Human capital, social capital, or cultural capital?.

Gabriel, S. A., Mattey, J. P., and Wascher, W. L. (2003). Compensating differentials and evolution in the quality-of-life among u.s. states. Regional Science and Urban Economics, 33(5):619 - 649.

Glaeser, E. L., Laibson, D., and Sacerdote, B. (2002). An economic approach to social capital. Economic Journal, 112(483):F437 - 58.

Goetzke, F. and Islam, S. (2017). Testing for spatial equilibrium using happiness data. Journal of Regional Science, 57(2).

Grislain-Lerémy, C. and Katossky, A. (2014). The impact of hazardous industrial facilities on housing prices: A comparison of parametric and semiparametric hedonic price models. Regional Science and Urban Economics, 49:93-107.

Haartsen, T., Huigen, P. P., and Groote, P. (2013). Rural areas in the netherlands. Tijdschrift voor Economische en Sociale Geografie, 94(1):129 - 136.

Haartsen, T. and Venhorst, V. (2010). Planning for decline: Anticipating on population decline in the netherlands. Tijdschrift voor Economische en Sociale Geografie, 101(2):218-227.

Hays, R. D. and Morales, L. S. (2001). The rand-36 measure of health-related quality of life. Annals of Medicine, 33(5):350357.

Helbich, M., Brunauer, W., Vaz, E., and Nijkamp, P. (2013). Spatial heterogeneity in hedonic house price models: The case of austria. Urban Studies, 51(2):390 - 411.

Hilber, C. A. L. (2010). New housing supply and the dilution of social capital. Journal of Urban Economics, 67(3):419 437.

Isen, A., Nygren, T., and Ashby, F. (1988). The influence of positive affect on the subjective utility of gains and losses: It's not worth the risk. Journal of Personality and Social Psychology, 55:710-717.

Jim, C. and Chen, W. Y. (2009). Value of scenic views: Hedonic assessment of private housing in hong kong. Landscape and Urban Planning, 91(4):226-234.

Kahneman, D. and Krueger, A. B. (2006). Developments in the measurement of subjective well-being. Journal of Economic Perspectives, 20(1):3-24. 
Kelejian, H. H. and Prucha, I. R. (2010). Specification and estimation of spatial autoregressive models with autoregressive and heteroskedastic disturbances. Journal of Econometrics, 157(1):53 - 67.

Klijs, B., Scholtens, S., Mandemakers, J. J., Snieder, H., Stolk, R. P., and Smidt, N. (2015). Representativeness of the lifelines cohort study. PLOS ONE, 10(9):1-12.

Lloyds Bank (2016). Living near a supermarket can bag you a $£ 22,000$ bonus on your home.

Luttmer, E. F. P. (2005). Neighbors as negatives: Relative earnings and well-being. Quarterly Journal of Economics, 120(3):963 - 1002.

Niedomysl, T. (2011). How migration motives change over migration distance: Evidence on variation across socio-economic and demographic groups. Regional Studies, 45(6):843-855.

NVM and VBO and VastgoedPRO and Vereniging Nederlandse Gemeenten and Waarderingskamer (2018). Meetinstructie bepalen woonoppervlak.

Nygren, T. E., Isen, A. M., Taylor, P. J., and Dulin, J. (1996). The influence of positive affect on the decision rule in risk situations: Focus on outcome (and especially avoidance of loss) rather than probability. Organizational Behavior and Human Decision Processes, 66(1):59-72.

Oswald, A. J. and Wu, S. (2010). Objective confirmation of subjective measures of human well-being: Evidence from the U.S.A. Science, 327(5965):576 - 579.

Panduro, T., Jensen, C., Lundhede, T., von Graevenitz, K., and Thorsen, B. (2018). Eliciting preferences for urban parks. Regional Science and Urban Economics, 73:127-142.

Piras, G. (2010). sphet: Spatial models with heteroskedastic innovations in r. Journal of Statistical Software, Articles, 35(1):1-21.

Rijnks, R. H., Koster, S., and McCann, P. (2018). Spatial heterogeneity in amenity and labor market migration. International Regional Science Review, 41(2):183-209.

Rijnks, R. H. and Strijker, D. (2013). Spatial effects on the image and identity of a rural area. Journal of Environmental Psychology, 36:103 - 111 .

Rosen, S. (1974). Hedonic prices and implicit markets: product differentiation in pure competition. Journal of Political Economy, 82(1):34-55.

Scholtens, S., Smidt, N., Swertz, M. A., Bakker, S. J., Dotinga, A., Vonk, J. M., van Dijk, F., van Zon, S. K., Wijmenga, C., Wolffenbuttel, B. H., and Stolk, R. P. (2015). Cohort profile: Lifelines, a three-generation cohort study and biobank. International Journal of Epidemiology, 44(4):1172-1180. 
Sen, A. (1987). The Standard of Living. Cambridge University Press, Cambridge.

Sheppard, S. (1999). Hedonic Analysis of Housing Markets, chapter 41, pages 1595 - 1635. Elsevier, Amsterdam, The Netherlands.

Stotz, O. (2019). The perception of homeownership utility: Short-term and long-term effects. Journal of Housing Economics, 44:99-111.

Stutzer, A. and Frey, B. S. (2008). Stress that doesn't pay: The commuting paradox. The Scandinavian Journal of Economics, 110(2):339-366.

Thissen, F., Fortuijn, J. D., Strijker, D., and Haartsen, T. (2010). Migration intentions of rural youth in the westhoek, flanders, belgium and the veenkoloniën, the netherlands. Journal of Rural Studies, 26(4):428 - 436.

Tivadar, M. and Jayet, H. (2019). Endogenous generation of amenities and the dynamics of city structure. Regional Science and Urban Economics, 74:49-56.

Tomkins, J., Topham, N., Twomey, J., and Ward, R. (1998). Noise versus access: The impact of an airport in an urban property market. Urban Studies, 35(2):243-258.

van Praag, B. M. and Baarsma, B. E. (2005). Using happiness surveys to value intangibles: The case of airport noise. The Economic Journal, 115(500):224 - 246.

Veenhoven, R. (2012). Happiness: Also known as "life satisfaction" and "subjective well-being". In Land, K. C., Michalos, A. C., and Sirgy, M. J., editors, Handbook of Social Indicators and Quality of Life Research, pages 63-77. Springer Netherlands, Dordrecht.

Vega, S. H. and Elhorst, J. P. (2015). The slx model. Journal of Regional Science, 55(3):339 - 363.

Watson, D. (1988). Intraindividual and interindividual analyses of positive and negative affect: Their relation to health complaints, perceived stress, and daily activities. Journal of Personality and Social Psychology, 54(6):1020 - 1030.

Yap, S. C. Y., Wortman, J., Anusic, I., Baker, S. G., Scherer, L. D., Donnellan, M. B., and Lucas, R. E. (2017). The effect of mood on judgments of subjective well-being: Nine tests of the judgment model. Journal of Personality and Social Psychology, 113(6):939 - 961. 